Please do not remove this page

RMIT

UNIVERSITY

\title{
Synthesis and pharmacology of new psychoactive substance 5F-CUMYL-P7AICA, a scaffold- hopping analog of synthetic cannabinoid receptor agonists 5F-CUMYL-PICA and 5F-CUMYL-PINACA
}

Banister, Samuel; Adams, Axel; Kevin, Richard; Macdonald, Christa; Glass, Michelle; Boyd, Rochelle; Connor, Mark

https://researchrepository.rmit.edu.au/esploro/outputs/9921861311901341/filesAndLinks?institution=61RMIT_INST\&index=null

Banister, S., Adams, A., Kevin, R., Macdonald, C., Glass, M., Boyd, R., Connor, M., McGregor, I., Havel, C., Bright, S., Vilamala, M., Lladanosa, C., Barratt, M., \& Gerona, R. (2019). Synthesis and pharmacology of new psychoactive substance 5F-CUMYL-P7AICA, a scaffold- hopping analog of synthetic cannabinoid receptor agonists 5F-CUMYL-PICA and 5F-CUMYL-PINACA. Drug Testing and Analysis, 11(2), 279-291.

https://doi.org/10.1002/dta.2491

Document Version: Submitted Version

Published Version: https://doi.org/10.1002/dta.2491

Repository homepage: https://researchrepository.rmit.edu.au

(c) 2018 John Wiley \& Sons, Ltd.

Downloaded On 2023/04/26 19:07:09 +1000 


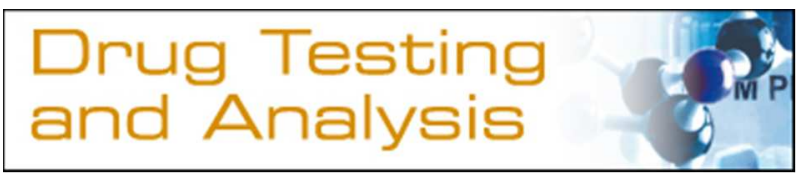

\section{Synthesis and pharmacology of synthetic cannabinoid 5F- CUMYL-P7AICA, a scaffold hopping analogue of 5F-CUMYL- PICA and 5F-CUMYL-PINACA}

\begin{tabular}{|c|c|}
\hline Journal: & Drug Testing and Analysis \\
\hline Manuscript ID & DTA-18-0047.R2 \\
\hline Wiley - Manuscript type: & Research Article \\
\hline Date Submitted by the Author: & $n / a$ \\
\hline Complete List of Authors: & $\begin{array}{l}\text { Banister, Samuel; Stanford University, Department of Pathology } \\
\text { Adams, Axel; University of California, San Francisco, Clinical Toxicology } \\
\text { and Environmental Biomonitoring Laboratory } \\
\text { Kevin, Richard; School of Psychology } \\
\text { Macdonald, Christa; The University of Auckland, School of Medical Sciences } \\
\text { Glass, Michelle; The University of Auckland, School of Medical Sciences } \\
\text { Boyd, Rochelle; Macquarie University Faculty of Medicine and Health } \\
\text { Sciences } \\
\text { Connor, Mark; Macquarie University Faculty of Medicine and Health } \\
\text { Sciences } \\
\text { McGregor, Iain; The University of Sydney, School of Psychology } \\
\text { Havel, Christopher; University of California, San Francisco, Department of } \\
\text { Clinical Pharmacology } \\
\text { Bright, Stephen; Edith Cowan University, School of Medical and Health } \\
\text { Science; Curtin University National Drug Research Institute, Faculty of } \\
\text { Health Sciences } \\
\text { Ventura, Mireia; Energy control barcelona } \\
\text { Gil, Cristina; Energy control barcelona } \\
\text { Barratt, Monica; UNSW, National Drug and Alcohol Research Centre; Curtin } \\
\text { University National Drug Research Institute, Faculty of Health Sciences; } \\
\text { Burnet Institute, Behaviours and Health Risks Program } \\
\text { Gerona, Roy; University of California, San Francisco, Clinical Toxicology } \\
\text { and Environmental Biomonitoring Laboratory }\end{array}$ \\
\hline Keywords: & $\begin{array}{l}\text { cannabinoid, CUMYL, PINACA, P7AICA, mass spectrometry, pharmacology, } \\
\text { scaffold hopping, biotelemetry }\end{array}$ \\
\hline Abstract: & $\begin{array}{l}\text { Synthetic cannabinoid receptor agonists (SCRAs) are a dynamic class of } \\
\text { new psychoactive substances (NPS), with novel chemotypes emerging each } \\
\text { year. Following the detection of 5F-CUMYL-P7AICA in Australia in 2016, the } \\
\text { Scaffold hopping SCRAs 5F-CUMY-PICA, 5F-CUMYL-PINACA, 5F-CUMY- } \\
\text { P7AICA were synthesized and characterized by nuclear magnetic resonance } \\
\text { (NMR) spectroscopy, gas chromatography-mass spectrometry (GC-MS), } \\
\text { and liquid chromatography-quadrupole time-of-flight-MS (LC-QTOF-MS). } \\
\text { Since little is known of the pharmacology of 7-azaindole SCRAs like 5F- } \\
\text { CUMYL-P7AICA, the binding affinities and functional activities of all } \\
\text { compounds at cannabinoid type } 1 \text { and type } 2 \text { receptors (CB1 and CB2 }\end{array}$ \\
\hline
\end{tabular}


respectively) were assessed using tritiated radioligand competition experiments and fluorescence-based plate reader membrane potential assays. Despite CB1 binding affinities differing by over two order of magnitude $(\mathrm{Ki}=2.95-174 \mathrm{nM})$, all compounds were potent and efficacious $\mathrm{CB} 1$ agonists $(\mathrm{EC} 50=0.43-4.7 \mathrm{nM})$, with consistent rank order for binding and functional activity (5F-CUMYL-PINACA > 5F-CUMYL-PICA > 5F-CUMYLP7AICA). Additionally, 5F-CUMYL-P7AICA was found to exert potent cannabimimetic effects in mice, inducing hypothermia $\left(6^{\circ} \mathrm{C}, 3 \mathrm{mg} / \mathrm{kg}\right)$ through a CB1-dependent mechanism.

\section{SCHOLARONE ${ }^{\text {tw }}$}

Manuscripts 


\title{
Synthesis and pharmacology of new psychoactive substance 5F-CUMYL-P7AICA, a scaffold hopping analogue of synthetic cannabinoid receptor agonists 5F-CUMYL-PICA and 5F-CUMYL-PINACA
}

\author{
Samuel D. Banister, ${ }^{a}$ Axel Adams, ${ }^{\mathrm{b}}$ Richard C. Kevin, ${ }^{\mathrm{c}}$ Christa Macdonald, ${ }^{\mathrm{d}}$ Michelle Glass, ${ }^{\mathrm{d}}$ \\ Rochelle Boyd, ${ }^{\mathrm{e}}$ Mark Connor, ${ }^{\mathrm{e}}$ Iain S. McGregor, ${ }^{\mathrm{c}}$ Christopher M. Havel, ${ }^{\mathrm{f}}$ Stephen J. Bright, ${ }^{\mathrm{g}, \mathrm{h}}$ \\ Mireia Ventura, ${ }^{\mathrm{i}}$ Cristina Gil, ${ }^{\mathrm{i}}$ Monica J. Barratt, ${ }^{\mathrm{j}, \mathrm{h}, \mathrm{k}}$ and Roy R. Gerona ${ }^{\mathrm{b}}$
}

${ }^{\mathrm{a}}$ Department of Pathology, Stanford University School of Medicine, Stanford, CA 94305, USA;

${ }^{\mathrm{b}}$ Clinical Toxicology and Environmental Biomonitoring Laboratory, University of California, San Francisco, CA 94143, USA; ' School of Psychology, The University of Sydney, Sydney, NSW 2006, Australia; ${ }^{\mathrm{d}}$ School of Medical Sciences, The University of Auckland, Auckland, New Zealand; ${ }^{\mathrm{e}}$ Faculty of Medicine and Health Sciences, Macquarie University, NSW 2109, Australia; ${ }^{\mathrm{f}}$ Department of Clinical Pharmacology, University of California, San Francisco, CA 94143, USA; ' School of Medical and Health Science, Edith Cowan University, Joondalup, Australia; ${ }^{\mathrm{h}}$ National Drug Research Institute, Faculty of Health Sciences, Curtin University, Perth, Australia; ${ }^{\mathrm{i} E n e r g y ~ C o n t r o l, ~ A s o c i a c i o ́ n ~ B i e n e s t a r ~ y ~ D e s a r r o l l o, ~ S p a i n ; ~}{ }^{\mathrm{j}}$ Drug Policy Modelling Program, National Drug and Alcohol Research Centre, UNSW, Sydney, NSW, Australia; ${ }^{\mathrm{k}}$ Behaviours and Health Risks Program, Burnet Institute, Melbourne, VIC, Australia

*Corresponding author 


\begin{abstract}
Synthetic cannabinoid receptor agonists (SCRAs) are a dynamic class of new psychoactive substances (NPS), with novel chemotypes emerging each year. Following the putative detection of 5F-CUMYL-P7AICA in Australia in 2016, the scaffold hopping SCRAs 5F-CUMYL-PICA， 5F-CUMYL-PINACA， 5F-CUMYL-P7AICA were synthesized and characterized by nuclear magnetic resonance (NMR) spectroscopy, gas chromatography-mass spectrometry (GC-MS), and liquid chromatography-quadrupole time-of-flight-MS (LC-QTOFMS). Since little is known of the pharmacology of 7-azaindole SCRAs like 5F-CUMYLP7AICA, the binding affinities and functional activities of all compounds at cannabinoid type 1 and type 2 receptors $\left(\mathrm{CB}_{1}\right.$ and $\mathrm{CB}_{2}$, respectively) were assessed using tritiated radioligand competition experiments and fluorescence-based plate reader membrane potential assays. Despite $\mathrm{CB}_{1}$ binding affinities differing by over two orders of magnitude $\left(K_{\mathrm{i}}=2.95-174 \mathrm{nM}\right)$, all compounds were potent and efficacious $\mathrm{CB}_{1}$ agonists $\left(\mathrm{EC}_{50}=0.43-4.7 \mathrm{nM}\right)$, with consistent rank order for binding and functional activity (5F-CUMYL-PINACA > 5F-CUMYL-PICA > 5FCUMYL-P7AICA). Additionally, 5F-CUMYL-P7AICA was found to exert potent cannabimimetic effects in mice, inducing hypothermia $\left(6^{\circ} \mathrm{C}, 3 \mathrm{mg} / \mathrm{kg}\right)$ through a $\mathrm{CB}_{1}$-dependent mechanism.
\end{abstract}

Keywords: cannabinoid, CUMYL, PINACA, P7AICA, scaffold hopping, mass spectrometry, pharmacology, biotelemetry 
Introduction: More than 230 synthetic cannabinoid receptor agonists (SCRAs) have been reported to the United Nations Office on Drugs and Crime (UNODC) as recreational drugs, ${ }^{1}$ representing the largest and most structurally diverse class of new psychoactive substances (NPS). The structural heterogeneity of SCRAs has increased since the first examples were identified in 2008, and novel chemotypes continue to emerge in an attempt to circumvent structure-based prohibition. $^{2}$ The earliest examples, such as 1-alkyl-3-acylindole JWH-018 (1, Figure 1), were repurposed from tool molecules described by John W. Huffman at Clemson University for studying cannabinoid receptors. Since then, many SCRAs with no precedent in the chemical literature, e.g. APICA (2) and BB-22 (3), have been reported. Most recently, SCRAs derived from a series of pharmaceutical patents (e.g. AMB-FUBINACA, 4) have been associated with serious adverse reactions. ${ }^{3}$

\section{[APPROXIMATE PLACEMENT OF FIGURE 1]}

One class of SCRAs increasingly identified by forensic scientists and clinical toxicologists are heteroaromatic carboxamides containing a pendant cumylamine group. ${ }^{4-7}$ The Slovenian National Focal Point notified the identification of 5F-CUMYL-PICA (5) through the European Monitoring Center for Drugs and Drug Addiction (EMCDDA) early warning system (EWS) on 23 September $2014 .^{8}$ The indazole analogue of 5F-CUMYL-PICA, 5F-CUMYL-PINACA (6), was notified by the Swedish EWS participants several weeks later. ${ }^{8}$ These compounds were previously reported in a 2014 patent as SGT-67 and SGT-25, respectively. ${ }^{9}$ Unexpectedly, 5FCUMYL-P7AICA (7), containing a 7-azaindole (pyrrolo[2,3-b]pyridine) core rather than an indole or indazole, was notified to the EWS in February $2015 .^{10}$ 5F-CUMYL-P7AICA does not 
appear in patent WO2014167530 or elsewhere in historical chemical literature, and may be the product of rational design by unknown parties.

In October 2016, legislation was implemented in Victoria, Australia to restrict SCRA products by prohibiting several structural classes, including indole- and indazole-3-carboxamides. However, by November 2016 new putative SCRA products were available, and a product branded "Rasta King" (Fig. 2a) was obtained by test purchase for the purpose of analysis. Gas chromatography-mass spectrometry (GC-MS) putatively identified 5F-CUMYL-P7AICA by comparison of GC retention time (total ion chromatogram, TIC) and MS fragmentation spectrum (Fig. 2b) with several public spectral libraries, and the internal mass spectral library of Energy Control. Comparison of the sample EI-MS spectrum to a spectral library cannot exclude certain structural isomers, however, neither 5F-CUMYL-P7AICA nor its regioisomers have been formally detected in Australia to date. This prompted us to characterize the chemistry and pharmacology of 5F-CUMYL-P7AICA and its scaffold hopping analogs 5F-CUMYL-PICA and 5F-CUMYL-PINACA, all of which have been previously detected in other parts of the world.

\section{[APPROXIMATE PLACEMENT OF FIGURE 2]}

Scaffold hopping is the technique of modifying the central core of a bioactive molecule to improve activity, and is commonly used by medicinal chemists during the drug discovery process. ${ }^{11,12}$ 5F-CUMYL-P7AICA is the first example of a pyrrolo[2,3-b]pyridine SCRA discovered as a putative NPS, and one of few reported examples of clandestine scaffold hopping. In this case, incorporation of a pyrrolo[2,3-b]pyridine core was possibly inspired by the 
cannabinoid activity of azaindoles previously reported by pharmaceutical scientists, ${ }^{13}$ and may represent an attempt to circumvent structure-based legislative changes.

SCRAs featuring pyrrolo[2,3-b]pyridine cores and other bicyclic heteroaromatic scaffolds continue to be reported, ${ }^{14-16}$ and little is known about their pharmacology and toxicology.,17-20 We prepared 5, 6, and 7, and investigated methods for discrimination of these analogues using nuclear magnetic resonance (NMR) spectroscopy, gas chromatograph-mass spectrometry (GCMS), and liquid chromatography-quadrupole time-of-flight-MS (LC-QTOF-MS). Additionally, we determined the binding affinities and functional activities of $\mathbf{5}, \mathbf{6}$, and $\mathbf{7}$, at human $\mathrm{CB}_{1}$ and $\mathrm{CB}_{2}$ receptors in vitro. Having previously described the cannabinoid activity of several cumylamine SCRAs in vivo, we used mouse biotelemetry to rank the relative potency of 7 compared to $\mathbf{5}$ and $\mathbf{6}$ in a living system.

\section{Experimental.}

General chemical synthesis details. All reactions were performed under an atmosphere of nitrogen or argon unless otherwise specified. Anhydrous dichloromethane, $N, N-$ dimethylformamide (DMF), methanol, and toluene were used as purchased. All other commercially available reagents (Sigma-Aldrich) were used as purchased. Analytical thin layer chromatography (TLC) was performed using Merck aluminum-backed silica gel 60 F254 (0.2 $\mathrm{mm})$ plates which were visualized using shortwave $(254 \mathrm{~nm})$ ultra-violet fluorescence. Flash chromatography was performed using Merck Kieselgel 60 (230-400 mesh) silica gel. Melting points were measured in open capillaries using a Laboratory Devices Mel-Temp II and are uncorrected. Nuclear magnetic resonance spectra were recorded at $298 \mathrm{~K}$ using an Agilent 400 
$\mathrm{MHz}$ spectrometer. The data are reported as chemical shift $(\delta \mathrm{ppm})$ relative to the residual protonated solvent resonance, relative integral, multiplicity $(\mathrm{s}=$ singlet, $\mathrm{br} \mathrm{s}=$ broad singlet, $\mathrm{d}=$ doublet, $\mathrm{t}=$ triplet, $\mathrm{q}=$ quartet, quin. $=$ quintet, sep $=$ septet, $\mathrm{m}=$ multiplet $)$, coupling constants $(J$ $\mathrm{Hz}$ ) and assignment. Assignment of signals was assisted by COSY, DEPT, HSQC, and HMBC experiments where necessary. Fourier-transform infrared (FTIR) spectroscopy data were previously reported for these compounds, with no remarkable spectral differences noted. ${ }^{15}$

1-(5-Fluoropentyl)- $N$-(2-phenylpropan-2-yl)-1H-indole-3-carboxamide (5). A solution of 1 (5-fluoropentyl)-1H-indole-3-carboxylic acid (10, $63 \mathrm{mg}, 0.25 \mathrm{mmol})$ in $\mathrm{CH}_{2} \mathrm{Cl}_{2}(2.5 \mathrm{~mL})$ was treated with $(\mathrm{COCl})_{2}(45 \mu \mathrm{L}, 0.5 \mathrm{mmol}, 2.0$ equiv.) followed by DMF (1 drop). After stirring for $2 \mathrm{~h}$, the solution was evaporated in vacuo, and the crude acid chloride was used immediately in the following step.

A cooled $\left(0^{\circ} \mathrm{C}\right)$ solution of the freshly prepared acid chloride $(0.25 \mathrm{mmol})$ in $\mathrm{CH}_{2} \mathrm{Cl}_{2}(2.5 \mathrm{~mL})$ was treated with $\mathrm{Et}_{3} \mathrm{~N}$ ( $88 \mu \mathrm{L}, 0.63$ mmol, 2.5 equiv.) and cumylamine ( $44 \mu \mathrm{L}, 0.3 \mathrm{mmol}, 1.2$ equiv.), and stirred at ambient temperature for $14 \mathrm{~h}$. The mixture was partitioned between $\mathrm{CH}_{2} \mathrm{Cl}_{2}(10 \mathrm{~mL})$ and $1 \mathrm{M}$ aq. $\mathrm{HCl}(5 \mathrm{~mL})$. The layers were separated and the organic phase was washed with $1 \mathrm{M}$ aq. $\mathrm{HCl}(2 \times 5 \mathrm{~mL})$, sat. aq. $\mathrm{NaHCO}_{3}(3 \times 5 \mathrm{~mL})$, brine $(5 \mathrm{~mL})$, dried $\left(\mathrm{MgSO}_{4}\right)$, and the solvent evaporated under reduced pressure. Following recrystallization from $i$ $\mathrm{PrOH}, 5$ was obtained as fine white needles (72 mg, 78\%). $\mathrm{R}_{f} 0.37$ (hexane-EtOAc, 50:50); m.p. 193-195 ${ }^{\circ} \mathrm{C} ;{ }^{1} \mathrm{H}$ NMR (400 MHz, $\left.\mathrm{CDCl}_{3}\right): \delta$ 7.92-7.90 (1H, m, ArH), $7.69(1 \mathrm{H}, \mathrm{s}, \mathrm{ArH}), 7.53-$ $7.50(2 \mathrm{H}, \mathrm{m}, \mathrm{ArH}), 7.40-7.33(3 \mathrm{H}, \mathrm{m}, \mathrm{ArH}), 7.30-7.22(3 \mathrm{H}, \mathrm{m}, \mathrm{ArH}), 6.28(1 \mathrm{H}, \mathrm{s}, \mathrm{NH}), 4.42$ $\left(2 \mathrm{H}, \mathrm{dt}, J=47.2,6.0 \mathrm{~Hz}, \mathrm{CH}_{2} \mathrm{~F}\right), 4.15\left(2 \mathrm{H}, \mathrm{t}, J=7.2 \mathrm{~Hz}, \mathrm{NCH}_{2}\right), 1.91(2 \mathrm{H}$, quin., $J=7.8 \mathrm{~Hz}$, 
$\left.\mathrm{CH}_{2}\right), 1.87\left(6 \mathrm{H}, \mathrm{s}, 2 \times \mathrm{CH}_{3}\right), 1.77-1.64\left(2 \mathrm{H}, \mathrm{m}, \mathrm{CH}_{2}\right), 1.49-1.41\left(2 \mathrm{H}, \mathrm{m}, \mathrm{CH}_{2}\right) ;{ }^{13} \mathrm{C}$ NMR $(100$ $\left.\mathrm{MHz}, \mathrm{CDCl}_{3}\right): \delta 164.4(\mathrm{CO}), 147.5$ (quat.), 136.7 (quat.), $131.8(\mathrm{CH}), 128.6(\mathrm{CH}), 126.7(\mathrm{CH})$, 125.3 (quat.), $125.0(\mathrm{CH}), 122.5(\mathrm{CH}), 121.5(\mathrm{CH}), 120.0(\mathrm{CH}), 112.0$ (quat.), $110.4(\mathrm{CH}), 83.8$ $\left(\mathrm{d},{ }^{1} J_{\mathrm{CF}}=165.0 \mathrm{~Hz}, \mathrm{CH}_{2} \mathrm{~F}\right), 56.2$ (quat.), $46.8\left(\mathrm{CH}_{2}\right), 30.1\left(\mathrm{~d},{ }^{2} J_{\mathrm{CF}}=19.9 \mathrm{~Hz}, \mathrm{CH}_{2}\right), 29.8(2 \times$ $\left.\mathrm{CH}_{3}\right), 29.8\left(\mathrm{CH}_{2}\right), 23.0\left(\mathrm{~d},{ }^{3} \mathrm{~J}_{\mathrm{CF}}=4.9 \mathrm{~Hz}, \mathrm{CH}_{2}\right)$.

General procedure for amidation of 1-(5-fluoropentyl)-1 $H$-indazole-3-carboxylic acid and 1-(5-fluoropentyl)-1H-pyrrolo[2,3-b]pyridine-3-carboxylic acid. To a solution of 1-(5fluoropentyl)-1H-indazole-3-carboxylic acid or 1-(5-fluoropentyl)-1H-pyrrolo[2,3-b]pyridine-3carboxylic acid $(0.25 \mathrm{mmol})$ in DMF $(1.25 \mathrm{~mL})$ was added $\mathrm{HOBt} \cdot \mathrm{H}_{2} \mathrm{O}(42 \mathrm{mg}, 0.28 \mathrm{mmol}, 1.1$ equiv.), $\mathrm{EDC} \cdot \mathrm{HCl}$ (63 mg, $0.33 \mathrm{mmol}, 1.3$ equiv.), cumylamine (40 $\mu \mathrm{L}, 0.28 \mathrm{mmol}, 1.1$ equiv.), and $\mathrm{Et}_{3} \mathrm{~N}(70 \mu \mathrm{L}, 0.50 \mathrm{mmol}, 2.0$ equiv.), and the mixture stirred at ambient temperature for 14 h. The mixture was poured onto $\mathrm{H}_{2} \mathrm{O}(60 \mathrm{~mL})$, extracted with EtOAc $(3 \times 10 \mathrm{~mL})$, and the combined organic were washed with $\mathrm{H}_{2} \mathrm{O}(2 \times 10 \mathrm{~mL})$, brine $(10 \mathrm{~mL})$, dried $\left(\mathrm{MgSO}_{4}\right)$, and the solvent evaporated under reduced pressure. The crude products were purified by flash chromatography.

1-(5-Fluoropentyl)- $N$-(2-phenylpropan-2-yl)-1H-indazole-3-carboxamide (6). Subjecting 1 (5-fluoropentyl)-1H-indazole-3-carboxylic acid $(\mathbf{1 5}, 63 \mathrm{mg}, 0.25 \mathrm{mmol})$ to the procedure above gave, following purification by flash chromatography (hexane-EtOAc 70:30), 6 as a colorless resin (75 mg, 82\%). $\mathrm{R}_{f} 0.65$ (hexane-EtOAc, 50:50); ${ }^{1} \mathrm{H}$ NMR (400 MHz, $\left.\mathrm{CDCl}_{3}\right): \delta 8.34(1 \mathrm{H}$, $\mathrm{dt}, J=8.2,0.9 \mathrm{~Hz}, \mathrm{ArH}), 7.53-7.50(2 \mathrm{H}, \mathrm{m}, \mathrm{ArH}), 7.43-7.32$ (5H, m, ArH, NH, overlapping), 7.26-7.20 (2H, m, ArH), $4.44\left(2 \mathrm{H}, \mathrm{dt}, J=47.3,6.0 \mathrm{~Hz}, \mathrm{CH}_{2} \mathrm{~F}\right), 4.41\left(2 \mathrm{H}, \mathrm{t}, J=7.1 \mathrm{~Hz}, \mathrm{NCH}_{2}\right)$, 
$2.01\left(2 \mathrm{H}\right.$, quin., $\left.J=7.6 \mathrm{~Hz}, \mathrm{CH}_{2}\right), 1.87\left(6 \mathrm{H}, \mathrm{s}, 2 \times \mathrm{CH}_{3}\right), 1.82-1.69\left(2 \mathrm{H}, \mathrm{m}, \mathrm{CH}_{2}\right), 1.53-1.45(2 \mathrm{H}$, m, $\left.\mathrm{CH}_{2}\right) ;{ }^{13} \mathrm{C} \mathrm{NMR}\left(100 \mathrm{MHz}, \mathrm{CDCl}_{3}\right): \delta 162.0$ (CO), 147.4 (quat.), 141.0 (quat.), 138.0 (quat.), $128.6(\mathrm{CH}), 126.8(\mathrm{CH}), 126.7(\mathrm{CH}), 125.0(\mathrm{CH}), 123.4(\mathrm{CH}), 123.0$ (quat.), $122.6(\mathrm{CH}), 109.1$ $(\mathrm{CH}), 83.9\left(\mathrm{~d},{ }^{1} J_{\mathrm{CF}}=165.0 \mathrm{~Hz}, \mathrm{CH}_{2} \mathrm{~F}\right), 55.9$ (quat.), $49.3\left(\mathrm{NCH}_{2}\right), 30.1\left(\mathrm{~d},{ }^{2} J_{\mathrm{CF}}=19.7 \mathrm{~Hz}, \mathrm{CH}_{2}\right)$, $29.8\left(2 \times \mathrm{CH}_{3}\right), 29.5\left(\mathrm{CH}_{2}\right), 22.9\left(\mathrm{~d},{ }^{3} J_{\mathrm{CF}}=5.0 \mathrm{~Hz}, \mathrm{CH}_{2}\right)$.

1-(5-Fluoropentyl)- $N$-(2-phenylpropan-2-yl)-1H-pyrrolo[2,3-b]pyridine-3-carboxamide $\quad(7$, 5F-CUMYL-P7AICA). Subjecting 1-(5-fluoropentyl)-1 $H$-pyrrolo[2,3-b]pyridine-3-carboxylic acid (16, $68 \mathrm{mg}, 0.25 \mathrm{mmol})$ to the procedure above gave, following purification by flash chromatography (hexane-EtOAc 50:50), 7 as a white crystalline solid (74 mg, 81\%). m.p. 174$176{ }^{\circ} \mathrm{C} ; \mathrm{R}_{f} 0.31$ (hexane-EtOAc, 50:50); ${ }^{1} \mathrm{H}$ NMR (400 MHz, $\left.\mathrm{CDCl}_{3}\right): \delta 8.36(1 \mathrm{H}, \mathrm{dd}, J=4.7$, 1.6 Hz, ArH), 8.27 (1H, dd, $J=8.0,1.6 \mathrm{~Hz}, \mathrm{ArH}), 7.74$ (1H, s, ArH), 7.52-7.49 (2H, m, ArH), 7.38-7.33 (2H, m, ArH), 7.27-7.23 (1H, m, ArH), $7.18(1 \mathrm{H}, \mathrm{dd}, J=8.0,4.7 \mathrm{~Hz}, \mathrm{ArH}), 6.14(1 \mathrm{H}$, br s, NH), $4.42\left(2 \mathrm{H}, \mathrm{dt}, J=47.3,6.0 \mathrm{~Hz}, \mathrm{CH}_{2} \mathrm{~F}\right.$, overlapped), $4.32\left(2 \mathrm{H}, \mathrm{t}, J=7.3 \mathrm{~Hz}, \mathrm{NCH}_{2}\right)$, $1.94\left(2 \mathrm{H}\right.$, quin., $\left.J=7.5 \mathrm{~Hz}, \mathrm{CH}_{2}\right), 1.86\left(6 \mathrm{H}, \mathrm{s}, 2 \times \mathrm{CH}_{3}\right), 1.81-1.66\left(2 \mathrm{H}, \mathrm{m}, \mathrm{CH}_{2}\right), 1.49-1.42(2 \mathrm{H}$, $\left.\mathrm{m}, \mathrm{CH}_{2}\right) ;{ }^{13} \mathrm{C} \mathrm{NMR}\left(100 \mathrm{MHz}, \mathrm{CDCl}_{3}\right): \delta 163.7$ (CO), 147.8 (quat.), 147.3 (quat.), $143.9(\mathrm{CH})$, $130.4(\mathrm{CH}), 128.9(\mathrm{CH}), 128.7(\mathrm{CH}), 126.8(\mathrm{CH}), 124.9(\mathrm{CH}), 118.3$ (quat.), $117.5(\mathrm{CH}), 110.3$ (quat.), 83.9 (d, $\left.{ }^{1} J_{\mathrm{CF}}=164.9 \mathrm{~Hz}, \mathrm{CH}_{2} \mathrm{~F}\right), 56.3$ (quat.), $45.0\left(\mathrm{NCH}_{2}\right), 30.1$ (d, ${ }^{2} J_{\mathrm{CF}}=19.8 \mathrm{~Hz}$, $\left.\mathrm{CH}_{2}\right), 30.0\left(\mathrm{CH}_{2}\right), 29.7\left(2 \times \mathrm{CH}_{3}\right), 22.8\left(\mathrm{~d},{ }^{3} J_{\mathrm{CF}}=5.0 \mathrm{~Hz}, \mathrm{CH}_{2}\right)$.

1-(5-Fluoropentyl)-1H-indole-3-carboxylic acid (10). To a cooled $\left(0{ }^{\circ} \mathrm{C}\right)$ suspension of sodium hydride (60\% dispersion in mineral oil, $120 \mathrm{mg}, 3.00 \mathrm{mmol}, 2.0$ equiv.) in DMF (1.5 mL) was added dropwise a solution of indole $(176 \mathrm{mg}, 1.50 \mathrm{mmol})$ in DMF $(0.2 \mathrm{~mL})$ and the mixture 
allowed to stir at ambient temperature for $10 \mathrm{~min}$. The mixture was cooled $\left(0{ }^{\circ} \mathrm{C}\right)$, treated dropwise with the appropriate 1-bromo-5-fluoropentane (195 $\mu \mathrm{L}, 1.58 \mathrm{mmol}, 1.05$ equiv.), and stirred at ambient temperature for $1 \mathrm{~h}$. The mixture was cooled $\left(0^{\circ} \mathrm{C}\right)$, treated portionwise with trifluoroacetic anhydride ( $521 \mu \mathrm{L}, 3.75 \mathrm{mmol}, 2.5$ equiv.), and stirred at ambient temperature for $1 \mathrm{~h}$. The solution was poured portionwise onto vigorously stirred ice-water $(90 \mathrm{~mL})$ until precipitation was complete, and the formed red-pink solid was filtered and air dried overnight.

To a refluxing solution of potassium hydroxide $(278 \mathrm{mg}, 4.95 \mathrm{mmol}, 3.3$ equiv.) in methanol $(0.55 \mathrm{~mL})$ was added portionwise a solution of the crude 1-(5-fluoropentyl)-3-trifluoroacetyl-1Hindole $(9,452 \mathrm{mg}, 1.50 \mathrm{mmol})$ in toluene $(1.25 \mathrm{~mL})$ and the solution heated at reflux for $2 \mathrm{~h}$. The solution was cooled to ambient temperature and partitioned between $1 \mathrm{M}$ aq. $\mathrm{NaOH}(40 \mathrm{~mL})$ and $\mathrm{Et}_{2} \mathrm{O}(5 \mathrm{~mL})$. The layers were separated, and the aqueous layer was adjusted to $\mathrm{pH} 1$ with $10 \mathrm{M}$ aq. $\mathrm{HCl}$. The aqueous phase was extracted with $\mathrm{Et}_{2} \mathrm{O}(3 \times 10 \mathrm{~mL})$, dried $\left(\mathrm{Na}_{2} \mathrm{SO}_{4}\right)$, and solvent evaporated under reduced pressure. The crude product was recrystallized from $i$-PrOH and gave 10 as a colorless crystalline solid $\left(249 \mathrm{mg}, 67 \%\right.$ over 2 steps). m.p. $120-122{ }^{\circ} \mathrm{C}$ (lit. m.p. $120-$ $\left.122{ }^{\circ} \mathrm{C}\right)^{21} ;{ }^{1} \mathrm{H}$ NMR $\left(400 \mathrm{MHz}, \mathrm{CDCl}_{3}\right): \delta 8.29-8.25(1 \mathrm{H}, \mathrm{m}, \mathrm{ArH}), 7.93(1 \mathrm{H}, \mathrm{s}, \mathrm{ArH}), 7.41-7.37$ $(1 \mathrm{H}, \mathrm{m}, \mathrm{ArH}), 7.34-7.30(2 \mathrm{H}, \mathrm{m}, \mathrm{ArH}), 4.43\left(2 \mathrm{H}, \mathrm{dt},{ }^{2} J_{\mathrm{HF}}=47.3,{ }^{3} J_{\mathrm{HH}}=5.9 \mathrm{~Hz}, \mathrm{CH}_{2} \mathrm{~F}\right), 4.18$ $\left(2 \mathrm{H}, \mathrm{t}, J=7.1 \mathrm{~Hz}, \mathrm{NCH}_{2}\right), 1.95\left(2 \mathrm{H}\right.$, quin., $\left.J=7.1 \mathrm{~Hz}, \mathrm{CH}_{2}\right), 1.78-1.68\left(2 \mathrm{H}, \mathrm{m}, \mathrm{CH}_{2}\right), 1.52-1.44$ $\left(2 \mathrm{H}, \mathrm{m}, \mathrm{CH}_{2}\right) ;{ }^{13} \mathrm{C} \mathrm{NMR}\left(100 \mathrm{MHz}, \mathrm{CDCl}_{3}\right): \delta 170.9$ (CO), 136.8 (quat.), $135.6(\mathrm{CH}), 127.1$ (quat.), $123.0(\mathrm{CH}), 122.3(\mathrm{CH}), 122.1(\mathrm{CH}), 110.1(\mathrm{CH}), 106.6$ (quat.), $83.8\left(\mathrm{~d},{ }^{1} J_{\mathrm{CF}}=165.2 \mathrm{~Hz}\right.$, $\left.\mathrm{CH}_{2} \mathrm{~F}\right), 47.1\left(\mathrm{CH}_{2}\right), 30.0\left(\mathrm{~d},{ }^{2} J_{\mathrm{CF}}=19.8 \mathrm{~Hz}, \mathrm{CH}_{2}\right), 29.6\left(\mathrm{CH}_{2}\right), 22.9\left(\mathrm{~d},{ }^{3} J_{\mathrm{CF}}=5.0 \mathrm{~Hz}, \mathrm{CH}_{2}\right)$. 
Methyl 1-(5-fluoropentyl)- $\boldsymbol{H} \boldsymbol{H}$-indazole-3-carboxylate (13). To a cooled $\left(0^{\circ} \mathrm{C}\right)$ solution of methyl $1 H$-indazole-3-caboxylate $(\mathbf{1 1}, 176 \mathrm{mg}, 1.00 \mathrm{mmol}, 1.0$ equiv.) in THF $(5.0 \mathrm{~mL})$ was added dropwise a $1 \mathrm{M}$ solution of potassium tert-butoxide in THF $(1.1 \mathrm{~mL}, 1.1 \mathrm{mmol}, 1.1$ equiv.), and the solution stirred at ambient temperature for $1 \mathrm{~h}$. The solution was cooled $\left(0{ }^{\circ} \mathrm{C}\right)$, treated dropwise with 1-bromo-5-fluoropentane (130 $\mu \mathrm{L}, 1.05 \mathrm{mmol}, 1.05$ equiv.), and stirred at ambient temperature for $14 \mathrm{~h}$. The mixture was partitioned between EtOAc $(10 \mathrm{~mL})$ and $\mathrm{H}_{2} \mathrm{O}(30$ $\mathrm{mL})$ and the layers separated. The aqueous layer was extracted with EtOAc $(3 \times 10 \mathrm{~mL})$, and the combined organic phases were washed with brine $(10 \mathrm{~mL})$, dried $\left(\mathrm{Na}_{2} \mathrm{SO}_{4}\right)$, and the solvent evaporated under reduced pressure affording, following purification by flash chromatography (hexane-EtOAc, 85:15), 13 as a colorless oil (206 mg, 78\%). $\mathrm{R}_{f} 0.51$ (hexane-EtOAc, 80:20); ${ }^{1} \mathrm{H}$ NMR (400 MHz, CDCl3): $\delta 8.24(1 \mathrm{H}, \mathrm{dt}, J=8.2,1.0 \mathrm{~Hz}), 7.49-7.42(2 \mathrm{H}, \mathrm{m}), 7.32(1 \mathrm{H}, \mathrm{ddd}, J=$ 8.2, 6.4, 1.4 Hz), $4.49\left(2 \mathrm{H}, \mathrm{t}, J=7.2 \mathrm{~Hz}, \mathrm{NCH}_{2}\right), 4.40\left(2 \mathrm{H}, \mathrm{dt},{ }^{2} J_{\mathrm{HF}}=47.3,{ }^{3} J_{\mathrm{HH}}=6.0 \mathrm{~Hz}, \mathrm{CH}_{2} \mathrm{~F}\right)$, $4.04\left(3 \mathrm{H}, \mathrm{s}, \mathrm{CH}_{3}\right), 2.02\left(2 \mathrm{H}\right.$, quin. $\left.J=7.6 \mathrm{~Hz}, \mathrm{CH}_{2}\right), 1.78-1.65\left(2 \mathrm{H}, \mathrm{m}, \mathrm{CH}_{2}\right), 1.50-1.42(2 \mathrm{H}, \mathrm{m}$, $\left.\mathrm{CH}_{2}\right) ;{ }^{13} \mathrm{C} \mathrm{NMR}\left(100 \mathrm{MHz}, \mathrm{CDCl}_{3}\right): \delta 163.1$ (CO), 140.5 (quat.), 134.6 (quat.), $126.9(\mathrm{CH})$, 123.7 (quat.), $123.1(\mathrm{CH}), 122.3(\mathrm{CH}), 109.6(\mathrm{CH}), 83.6\left(\mathrm{~d},{ }^{1} J_{\mathrm{CF}}=165.0 \mathrm{~Hz}, \mathrm{CH}_{2} \mathrm{~F}\right), 52.0\left(\mathrm{CH}_{3}\right)$, $49.7\left(\mathrm{NCH}_{2}\right), 29.9\left(\mathrm{~d},{ }^{2} J_{\mathrm{CF}}=19.8 \mathrm{~Hz}, \mathrm{CH}_{2}\right), 29.5\left(\mathrm{CH}_{2}\right), 22.7\left(\mathrm{~d},{ }^{3} J_{\mathrm{CF}}=5.2 \mathrm{~Hz}, \mathrm{CH}_{2}\right)$.

Methyl 1-(5-fluoropentyl)-1H-pyrrolo[2,3-b]pyridine-3-carboxylate (14). A cooled $\left(0{ }^{\circ} \mathrm{C}\right)$ solution of methyl 1H-pyrrolo[2,3-b]pyridine-3-carboxylate $(\mathbf{1 2}, 126 \mathrm{mg}, 1.00 \mathrm{mmol})$ in DMF (5 $\mathrm{mL})$ was treated portionwise with $\mathrm{NaH}(60 \%$ dispersion in mineral oil, $44 \mathrm{mg}, 1.10 \mathrm{mmol}, 1.1$ equiv.) and stirred at ambient temperature for $1 \mathrm{~h}$. The mixture was cooled $\left(0^{\circ} \mathrm{C}\right)$ and treated dropwise with 1-bromo-5-fluoropentane (178 mg, $1.05 \mathrm{mmol}, 1.05$ equiv.). After stirring at ambient temperature for $24 \mathrm{~h}$, the mixture was poured onto $\mathrm{H}_{2} \mathrm{O}(100 \mathrm{~mL})$ and extracted with 
EtOAc $(3 \times 15 \mathrm{~mL})$. The combined organic extracts were washed with $\mathrm{H}_{2} \mathrm{O}(2 \times 15 \mathrm{~mL})$, brine $(15 \mathrm{~mL})$, dried $\left(\mathrm{MgSO}_{4}\right)$, and solvent evaporated under reduced pressure. The crude material was purified by flash chromatography (hexane-EtOAc 50:50) to give $\mathbf{1 4}$ as a colorless oil (175 $\mathrm{mg}$, $66 \%$ ). $\mathrm{R}_{f} 0.43$ (hexane-EtOAc, 50:50); ${ }^{1} \mathrm{H}$ NMR (400 MHz, $\mathrm{CDCl}_{3}$ ): $\delta 8.41(1 \mathrm{H}, \mathrm{dd}, J=7.9,1.6$ $\mathrm{Hz}, \mathrm{ArH}), 8.37(1 \mathrm{H}, \mathrm{dd}, J=4.7,1.6 \mathrm{~Hz}, \mathrm{ArH}), 7.94(1 \mathrm{H}, \mathrm{s}, \mathrm{ArH}), 7.21(1 \mathrm{H}, \mathrm{dd}, J=7.9,4.7 \mathrm{~Hz}$, ArH), $4.41\left(2 \mathrm{H}, \mathrm{dt}, J=47.3,6.0 \mathrm{~Hz}, \mathrm{CH}_{2} \mathrm{~F}\right.$, overlapped), $4.34\left(2 \mathrm{H}, \mathrm{t}, J=7.2 \mathrm{~Hz}, \mathrm{NCH}_{2}\right), 3.91$ $\left(3 \mathrm{H}, \mathrm{s}, \mathrm{CH}_{3}\right), 1.96\left(2 \mathrm{H}\right.$, quin., $\left.J=7.5 \mathrm{~Hz}, \mathrm{CH}_{2}\right), 1.80-1.66\left(2 \mathrm{H}, \mathrm{m}, \mathrm{CH}_{2}\right), 1.50-1.42(2 \mathrm{H}, \mathrm{m}$, $\left.\mathrm{CH}_{2}\right) ;{ }^{13} \mathrm{C} \mathrm{NMR}\left(100 \mathrm{MHz}, \mathrm{CDCl}_{3}\right): \delta 165.1(\mathrm{CO}), 147.8$ (quat.), $144.1(\mathrm{CH}), 134.1(\mathrm{CH}), 130.1$ (CH), 119.2 (quat.), $118.1(\mathrm{CH}), 105.7$ (quat.), $83.8\left(\mathrm{~d},{ }^{1} J_{\mathrm{CF}}=165.0 \mathrm{~Hz}, \mathrm{CH}_{2} \mathrm{~F}\right), 51.3\left(\mathrm{CH}_{3}\right), 45.2$ $\left(\mathrm{NCH}_{2}\right), 30.1\left(\mathrm{~d},{ }^{2} J_{\mathrm{CF}}=19.8 \mathrm{~Hz}, \mathrm{CH}_{2}\right), 29.9\left(\mathrm{CH}_{2}\right), 22.7\left(\mathrm{~d},{ }^{3} J_{\mathrm{CF}}=5.2 \mathrm{~Hz}, \mathrm{CH}_{2}\right)$.

1-(5-Fluoropentyl)-1H-indazole-3-carboxylic acid (15). To a solution of 13 (198 mg, 0.75 $\mathrm{mmol})$ in $\mathrm{MeOH}(7.5 \mathrm{~mL})$ was added $1 \mathrm{M}$ aq. $\mathrm{NaOH}(3.0 \mathrm{~mL})$ in a single portion, and the solution stirred at ambient temperature for $16 \mathrm{~h}$. The solvent was evaporated under reduced pressure, the crude material dissolved in $\mathrm{H} 2 \mathrm{O}(30 \mathrm{~mL})$, and the $\mathrm{pH}$ adjusted to 2 with $10 \mathrm{M}$ aq. $\mathrm{HCl}$. The aqueous phase was extracted with EtOAc $(3 \times 10 \mathrm{~mL})$, and the combined organic layers were washed with brine $(5 \mathrm{~mL})$, dried $\left(\mathrm{Na}_{2} \mathrm{SO}_{4}\right)$, and the solvent evaporated under reduced pressure to afford 13 as a white powder (185 mg, 98\%). m.p. 80-82 ${ }^{\circ} \mathrm{C} ;{ }^{1} \mathrm{H}$ NMR (400 MHz, $\left.\mathrm{CDCl}_{3}\right): \delta 8.27(1 \mathrm{H}, \mathrm{dt}, J=8.2,1.0 \mathrm{~Hz}, \mathrm{ArH}), 7.52-7.46(2 \mathrm{H}, \mathrm{m}, \mathrm{ArH}), 7.37(1 \mathrm{H}, \mathrm{ddd}, J=8.2$, 6.2, 1.7 Hz, ArH), $4.52\left(2 \mathrm{H}, \mathrm{t}, J=7.2 \mathrm{~Hz}, \mathrm{NCH}_{2}\right), 4.43\left(2 \mathrm{H}, \mathrm{dt}, J=47.3,6.0 \mathrm{~Hz}, \mathrm{CH}_{2} \mathrm{~F}\right), 2.06$ (2H, quin., $\left.J=7.6 \mathrm{~Hz}, \mathrm{CH}_{2}\right), 1.81-1.67\left(2 \mathrm{H}, \mathrm{m}, \mathrm{CH}_{2}\right), 1.52-1.44\left(2 \mathrm{H}, \mathrm{m}, \mathrm{CH}_{2}\right) ;{ }^{13} \mathrm{C} \mathrm{NMR}(100$ $\left.\mathrm{MHz}, \mathrm{CDCl}_{3}\right): \delta 166.4(\mathrm{CO}), 141.0$ (quat.), 134.1 (quat.), $127.2(\mathrm{CH}), 124.0(\mathrm{CH}), 123.7(\mathrm{CH})$, 
122.5 (quat.), $109.8(\mathrm{CH}), 83.8\left(\mathrm{~d},{ }^{1} J_{\mathrm{CF}}=165.0 \mathrm{~Hz}, \mathrm{CH}_{2} \mathrm{~F}\right), 50.0\left(\mathrm{NCH}_{2}\right), 30.1\left(\mathrm{~d},{ }^{2} J_{\mathrm{CF}}=19.8 \mathrm{~Hz}\right.$, $\left.\mathrm{CH}_{2}\right), 29.5\left(\mathrm{CH}_{2}\right), 22.9\left(\mathrm{~d},{ }^{3} J_{\mathrm{CF}}=5.0 \mathrm{~Hz}, \mathrm{CH}_{2}\right)$.

1-(5-Fluoropentyl)-1H-pyrrolo[2,3-b]pyridine-3-carboxylic acid (16). A solution of 14 (175 mg, $0.66 \mathrm{mmol})$ in $\mathrm{MeOH}(8 \mathrm{~mL})$ was treated with $1 \mathrm{M}$ aq. $\mathrm{NaOH}(4 \mathrm{~mL}, 4 \mathrm{mmol}, 6$ equiv. $)$ and stirred at ambient temperature for $96 \mathrm{~h}$. The solvent was evaporated under reduced pressure and the crude material added to $\mathrm{H}_{2} \mathrm{O}(15 \mathrm{~mL})$. The solution was adjusted to $\mathrm{pH} 2$ with $10 \mathrm{M}$ aq. $\mathrm{HCl}$, and the aqueous phase was extracted with $\mathrm{CHCl}_{3}(3 \times 15 \mathrm{~mL})$. The combined organic extracts were dried $\left(\mathrm{MgSO}_{4}\right)$ and the solvent evaporated under reduced pressure to give 16 (155 $\mathrm{mg}$, 94\%) as a white solid. m.p. ${ }^{143-145}{ }^{\circ} \mathrm{C} ;{ }^{1} \mathrm{H}$ NMR (400 MHz, $\left.\mathrm{CDCl}_{3}\right): \delta 8.48(1 \mathrm{H}, \mathrm{dd}, J=7.9$, $1.6 \mathrm{~Hz}, \mathrm{ArH}), 8.42(1 \mathrm{H}, \mathrm{dd}, J=4.7,1.6 \mathrm{~Hz}, \mathrm{ArH}), 8.05(1 \mathrm{H}, \mathrm{s}, \mathrm{ArH}), 7.26(1 \mathrm{H}, \mathrm{dd}, J=7.9,4.7$ $\mathrm{Hz}, \mathrm{ArH}), 4.43\left(2 \mathrm{H}, \mathrm{dt}, J=47.3,6.0 \mathrm{~Hz}\right.$, overlapped, $\left.\mathrm{CH}_{2} \mathrm{~F}\right), 4.38\left(2 \mathrm{H}, \mathrm{t}, J=7.2 \mathrm{~Hz}, \mathrm{NCH}_{2}\right)$, $1.99\left(2 \mathrm{H}\right.$, quin., $\left.\mathrm{J}=7.5 \mathrm{~Hz}, \mathrm{CH}_{2}\right), 1.80-1.70\left(2 \mathrm{H}, \mathrm{m}, \mathrm{CH}_{2}\right), 1.53-1.47\left(2 \mathrm{H}, \mathrm{m}, \mathrm{CH}_{2}\right) ;{ }^{13} \mathrm{C} \mathrm{NMR}$ (100 MHz, $\left.\mathrm{CDCl}_{3}\right): \delta 169.6(\mathrm{CO}), 148.0$ (quat.), $144.3(\mathrm{CH}), 135.3(\mathrm{CH}), 130.3(\mathrm{CH}), 119.5$ (quat.), $118.4(\mathrm{CH}), 105.1$ (quat.), $83.8\left(\mathrm{~d},{ }^{1} J_{\mathrm{CF}}=165.0 \mathrm{~Hz}, \mathrm{CH}_{2} \mathrm{~F}\right), 45.4\left(\mathrm{NCH}_{2}\right), 30.1\left(\mathrm{~d},{ }^{2} J_{\mathrm{CF}}=\right.$ $\left.19.8 \mathrm{~Hz}, \mathrm{CH}_{2}\right), 29.9\left(\mathrm{CH}_{2}\right), 22.8\left(\mathrm{~d},{ }^{3} J_{\mathrm{CF}}=5.1 \mathrm{~Hz}, \mathrm{CH}_{2}\right)$.

GC-MS analysis method for herbal product obtained by test purchase. A portion of the "Rasta King" SCRA herbal product (24.2 mg) obtained by test purchase was dissolved in $10 \mathrm{~mL}$ of methanol in a glass vial, sonicated for 15 minutes, and centrifuged for $10 \mathrm{~min}$ at $3500 \mathrm{rpm}$. The supernatant was analyzed using gas chromatography-mass spectrometry (GC-MS) on an Agilent 7890B gas chromatograph coupled to a 5977A quadrupole mass spectrometer detector (Agilent; Santa Clara, CA, USA). The gas chromatograph was fitted with a G4513A auto- 
sampler injector. Insert liners packed with silanized glasswool were used, and the injector and the interface were operated at $280{ }^{\circ} \mathrm{C}$. One $\mu \mathrm{L}$ of sample was injected in split mode, with a split ratio 1:10, into a $20 \mathrm{~m}, 0.18 \mathrm{~mm}$ i.d., $0.18 \mu \mathrm{m}$ film thickness $5 \%$ phenylmethylsilicone column (HP-5MS UI-1909S-577UI, Fast type, Agilent Technologies). Helium was used as carrier gas at a flow rate of $0.6 \mathrm{~mL} / \mathrm{min}$. The oven temperature was initially maintained at $90{ }^{\circ} \mathrm{C}$ and programmed to reach $320{ }^{\circ} \mathrm{C}$ at $25{ }^{\circ} \mathrm{C}$ per min. It was finally maintained at $320{ }^{\circ} \mathrm{C}$ for $3 \mathrm{~min}$ (total run time was $15.2 \mathrm{~min}$ ). Subsequently a 3-minute post run at $320{ }^{\circ} \mathrm{C}$. The mass spectrometer was operated in electronic ionization mode at $70 \mathrm{eV}$. MS system worked in SCAN acquisition mode, acquiring from $\mathrm{m} / \mathrm{z} 40$ to $400 \mathrm{Da}$. The obtained spectrum was compared to the Searchable Mass Spectral Library NIST/EPA/NIH Mass Spectral Library, Data Version: NIST 14; Searchable Mass Spectral Library Version 3.1 (http://www.swgdrug.org/ms.htm), Searchable Mass Spectral Library Cayman Spectral Library (CSL) (https://www.caymanchem.com/app/template/SpectralLibrary.vm), European project RESPONSE (http://www.policija.si/apps/nfl_response_web/seznam.php) and Energy Control's internal mass spectral library.

GC-MS analysis acquisition and analysis method for synthesized standards. Synthetic standards were dissolved to in methanol $(10 \mu \mathrm{g} / \mathrm{mL})$, and samples were analyzed using a Thermo Scientific TRACE 1300 Series gas chromatograph coupled to a Thermo Scientific TSQ 8000 Evo Triple Quadrupole mass spectrometer system (Thermo Fisher Scientific, Waltham, MA, USA). The injector and the interface were operated at $280^{\circ} \mathrm{C}$. One $\mu \mathrm{L}$ of sample were injected in split mode, with a splitless, into a $30 \mathrm{~m}, 0.25 \mathrm{~mm}$ i.d., $0.18 \mu \mathrm{m}$ film thickness $5 \%$ phenylmethylsilicone column (HP-5MS UI-19091S-577UI, P/N 19091S-433 Agilent J\&W 
Technologies). Helium was used as carrier gas at a flow rate of $1.2 \mathrm{~mL} / \mathrm{min}$. The oven temperature was ramped from $100{ }^{\circ} \mathrm{C}$ to $320^{\circ} \mathrm{C}$ at $33.3{ }^{\circ} \mathrm{C}$ per min. It was maintained at $320^{\circ} \mathrm{C}$ for $5 \mathrm{~min}$ for a total run time of $11.6 \mathrm{~min}$, followed by a $5 \mathrm{~min}$ post run at $320^{\circ} \mathrm{C}$. The mass spectrometer was operated in electronic ionization mode at $70 \mathrm{eV}$. MS system worked in SCAN acquisition mode, acquiring from $\mathrm{m} / \mathrm{z} 40$ to $400 \mathrm{Da}$.

LC-QTOF/MS acquisition and analysis method for synthesized standards. All samples were analyzed using an Agilent LC 1260 Infinity Binary Liquid Chromatograph (LC) System attached to an Agilent 6550 iFunnel Quadrupole Time-of-Flight Mass Spectrometer (QTOF/MS) 6550 (Agilent Technologies, Santa Clara, CA). An Agilent jet stream electrospray ionization (ESI) source with a dual nebulizer that allows constant introduction of reference mass during sample run was used to ionize sample organic components in positive mode.

Each sample was prepared from a crystalline aliquot of purified synthetic product and diluted to a final concentration of 100 and $10 \mathrm{ng} / \mathrm{mL}$ in $10 \%$ LC-MS grade acetonitrile (Honeywell B\&J, Muskegon, MI); two concentrations were injected to elucidate potential solvent impurities or instrument artifacts, and to ensure that similar fragmentation spectra are obtained at concentrations relevant for the analysis of biological samples. In each sample run, $2.5 \mu \mathrm{L}$ was injected into an Agilent Poroshell $120 \mathrm{C}-18$ column $(2.1 \times 100 \mathrm{~mm}, 2.7 \mu \mathrm{m})$ maintained at 50 ${ }^{\circ} \mathrm{C}$. Chromatographic separation was achieved by gradient elution using LC-MS grade water (Honeywell B\&J, Muskegon, MI) with $0.05 \%$ formic acid and $5 \mathrm{mM}$ ammonium formate as mobile phase A, and acetonitrile with $0.05 \%$ formic acid as mobile phase $\mathrm{B}$. The elution gradient used was $0-0.5 \min =5 \% \mathrm{~B} ; 1.5 \min =30 \% \mathrm{~B} ; 4.5 \min =70 \% \mathrm{~B} ; 7.5 \min =100 \% \mathrm{~B} ; 7.5-10$ 
$\min =100 \% \mathrm{~B}$; and $10.01-12 \min =5 \% \mathrm{~B}$.

Ionization of chromatographic eluates was induced on the QTOF/MS using an ESI source in the positive mode operated under the following conditions: gas temperature at $225^{\circ} \mathrm{C}$; sheath gas temperature at $350^{\circ} \mathrm{C}$; drying gas flow at $14 \mathrm{~L} / \mathrm{min}$; sheath gas flow at $11 \mathrm{~L} / \mathrm{min}$; nebulizer pressure at 40 psig; voltage cap at $3000 \mathrm{~V}$; and nozzle voltage at $500 \mathrm{~V}$. Data acquisition was run at $2 \mathrm{GHz}$ in extended dynamic range mode. Both TOF/MS and MS/MS spectra were collected in automated MS/MS mode using 500 arbitrary units as threshold for inducing MS/MS data collection. An active exclusion was used after 1 spectra, with a release time of 0.05 min. Each sample was run in triplicate.

To detect the analyte of interest and any impurities, the total ion chromatogram (TIC) obtained from the LC-QTOF/MS run was analyzed using Agilent MassHunter Qualitative Analysis software (Agilent Technologies, Sta. Clara, CA). A search was done using the chemical formula of the expected material to confirm the identity and measure retention time of the major chromatogram peak. To confirm, the following criteria were imposed for a compound match: mass error $\leq 10 \mathrm{ppm}$; target score $\geq 70$ (indication of mass and isotopic pattern matches) for peaks that did not exhibit detector saturation; and the presence of at least one expected fragment ion peak in its MS/MS spectra. MS/MS spectra were captured to assess the unique fragmentation of each parent cannabinoid.

In vitro cannabinoid receptor binding experiments. Experiments utilized human $\mathrm{CB}_{1}$ or $\mathrm{CB}_{2}$ tagged at the $N$-terminus with three haemagglutinin sequences $\left(\mathrm{HA}-\mathrm{hCB}_{1}, \mathrm{HA}-\mathrm{hCB}_{2}\right)$ stably 
transfected into HEK $293^{22,23}$. HEK 293 were cultivated in Dulbecco's Modified Eagle's Medium (DMEM) supplemented with 10\% fetal bovine serum (FBS) and zeocin, $(250 \mu \mathrm{g} / \mathrm{mL})$. Cells were maintained in $5 \% \mathrm{CO} 2$ at $37^{\circ} \mathrm{C}$ in a humidified atmosphere. Cells were grown in 75 mm2 flasks and passaged when $80-90 \%$ confluent.

HEK 293-hCB 1 or $\mathrm{HEK} 293-\mathrm{hCB}_{2}$ cells were grown to $90-100 \%$ confluence in $175 \mathrm{~cm}^{2}$ flasks and harvested in ice-cold phosphate buffered saline (PBS) with $5 \mathrm{mM}$ EDTA. Cells were centrifuged at $200 \times \mathrm{g}$ for 10 minutes and the pellet frozen at $-80{ }^{\circ} \mathrm{C}$ until required. Pellets were thawed with Tris-sucrose buffer $(50 \mathrm{mM}$ Tris- $\mathrm{HCl}, \mathrm{pH} 7.4,200 \mathrm{mM}$ sucrose, $5 \mathrm{mM} \mathrm{MgCl} 2,2.5$ mM EDTA) and homogenized with a glass homogenizer. The homogenate was centrifuged at $1000 \times \mathrm{g}$ for 10 minutes at $4{ }^{\circ} \mathrm{C}$ and the pellet discarded. The supernatant was then centrifuged at $27000 \times \mathrm{g}$ for 30 minutes at $4{ }^{\circ} \mathrm{C}$. The final pellet was resuspended in a minimal volume of Trissucrose buffer, and aliquoted then stored at $-80{ }^{\circ} \mathrm{C}$. Protein concentration was determined using the DC protein assay kit (Bio-Rad, Hercules, CA, USA) following the manufacturers protocol. Initial compound screening involved resuspending cell membranes ( $5 \mu \mathrm{g} /$ point $)$ in binding buffer (50 mM HEPES, $1 \mathrm{mM} \mathrm{MgCl2,} 1 \mathrm{mM} \mathrm{CaCl2}, 0.2 \%(\mathrm{w} / \mathrm{v})$ bovine serum albumin (BSA, ICP Bio, New Zealand, $\mathrm{pH}$ 7.4) and incubating with $\left[{ }^{3} \mathrm{H}\right] \mathrm{SR} 141716 \mathrm{~A}(1.25 \mathrm{nM})$ for $\mathrm{CB}_{1}$ or $\left[{ }^{3} \mathrm{H}\right] \mathrm{CP} 55,940(1.0 \mathrm{nM})$ for $\mathrm{CB}_{2}$ (PerkinElmer, Waltham, MA, USA; specific activity) and 10 $\mu \mathrm{M}$ of the test compound at $30{ }^{\circ} \mathrm{C}$ for 60 minutes. GF/C Harvest Plates (PerkinElmer) were presoaked in $0.1 \%$ polyethylenimine for one hour and then washed with $200 \mu \mathrm{L}$ ice cold wash buffer (50 mM HEPES pH $7.4500 \mathrm{mM} \mathrm{NaCl}, 0.1 \%$ BSA) prior to filtration of samples, which were then subject to 3 additional $200 \mu \mathrm{L}$ washes in ice cold wash buffer. Harvest plates were dried overnight at $24{ }^{\circ} \mathrm{C}$, then $50 \mu \mathrm{L}$ of scintillation fluid (Irgasafe Plus; PerkinElmer) was added 
to each well and plates were read 30 minutes later for 2 minutes per well in a Microbeta Trilux (PerkinElmer). Screening assays were performed in duplicate, repeating assays for each mediator 3 or more times. Non-specific binding was defined as binding that occurred in the presence of $10 \mu \mathrm{M} \mathrm{CP} 55,940$. Compounds that produced $>60 \%$ displacement at $10 \mu \mathrm{M}$ were further characterized to define affinity. Concentration response curves were carried out by incubating the membranes and radioligand with a range of concentrations of test compound. Data was analyzed using GraphPad Prism, curves are generated using a One site-fit $K_{\mathrm{i}}$ Competitive Binding function with $K_{\mathrm{d}}$ of $\left[{ }^{3} \mathrm{H}\right] \mathrm{SR} 141716 \mathrm{~A}$ constrained to $1.0 \mathrm{nM}$ at $\mathrm{CB}_{1}$, and $\left[{ }^{3} \mathrm{H}\right] \mathrm{CP} 55,940$ at $1.0 \mathrm{nM}$ at $\mathrm{CB}_{2}$.

In vitro cannabinoid receptor functional activity assay. Mouse AtT20 neuroblastoma cells stably transfected with human $\mathrm{CB}_{1}$ or human $\mathrm{CB}_{2}$ have been previously described, ${ }^{24}$ and were cultured in Dulbecco's modified Eagle's medium (DMEM) containing 10\% fetal bovine serum (FBS), $100 \mathrm{U}$ penicillin/streptomycin, and $80 \mathrm{mg} / \mathrm{ml}$ hygromycin. Cells were passaged at $80 \%$ confluency as required. Cells for assays were grown in $75 \mathrm{~cm}^{2}$ flasks and used at $90 \%$ confluence. The day before the assay cells were detached from the flask with trypsin/EDTA (Sigma) and resuspended in $10 \mathrm{~mL}$ of Leibovitz's L-15 media supplemented with 1\% FBS, 100 U penicillin/streptomycin and $15 \mathrm{mM}$ glucose. The cells were plated in volume of $90 \mu \mathrm{L}$ in black walled, clear bottomed 96-well microplates (Corning) which had been precoated with poly-Llysine (Sigma, Australia). Cells were incubated overnight at $37^{\circ} \mathrm{C}$ in ambient $\mathrm{CO}_{2}$.

Membrane potential was measured using a FLIPR Membrane Potential Assay kit (blue) from Molecular Devices, as described previously. ${ }^{25}$ The dye was reconstituted with assay buffer of 
composition (mM): $\mathrm{NaCl}$ 145, HEPES 22, $\mathrm{Na}_{2} \mathrm{HPO}_{4}$ 0.338, $\mathrm{NaHCO}_{3} 4.17, \mathrm{KH}_{2} \mathrm{PO}_{4} 0.441$, $\mathrm{MgSO}_{4}$ 0.407, $\mathrm{MgCl}_{2}$ 0.493, $\mathrm{CaCl}_{2}$ 1.26, glucose 5.56 (pH 7.4, osmolarity $315 \pm 5$ ). Prior to the assay, cells were loaded with $90 \underline{\mu} \mathrm{L} /$ well of the dye solution without removal of the L-15, giving an initial assay volume of $180 \mu \mathrm{L} /$ well. Plates were then incubated at $37^{\circ} \mathrm{C}$ at ambient $\mathrm{CO}_{2}$ for 45 min. Fluorescence was measured using a FlexStation 3 (Molecular Devices) microplate reader with cells excited at a wavelength of $530 \mathrm{~nm}$ and emission measured at $565 \mathrm{~nm}$. Baseline readings were taken every $2 \mathrm{~s}$ for at least $2 \mathrm{~min}$, at which time either drug or vehicle was added in a volume of $20 \mu \mathrm{L}$. The background fluorescence of cells without dye or dye without cells was negligible. Changes in fluorescence were expressed as a percentage of baseline fluorescence after subtraction of the changes produced by vehicle addition, which was less than $2 \%$ for drugs dissolved in assay buffer or DMSO. The final concentration of DMSO was not more than $0.1 \%$.

Data were analyzed with PRISM (GraphPad Software Inc., San Diego, CA), using fourparameter nonlinear regression to fit concentration-response curves. In all plates, a maximally effective concentration of CP 55,940 was added to allow for normalization between assays.

\footnotetext{
In vivo pharmacological assessment of 5F-CUMYL-P7AICA. Four adult male (C57BL/6J) mice (Animal Resources Centre, Perth, Australia) were used for biotelemetric assessment of body temperature following 5F-CUMYL-P7AICA administration. Initially, mice weighed between 21.2 and $29.5 \mathrm{~g}$. The mice were singly housed in a climate-controlled testing room ( $23 \pm$ $1{ }^{\circ} \mathrm{C}$ ) on a $12 \mathrm{~h} \mathrm{light/dark} \mathrm{cycle} \mathrm{(lights} \mathrm{on} \mathrm{from} \mathrm{07:00} \mathrm{to} \mathrm{19:00).} \mathrm{Water} \mathrm{and} \mathrm{standard} \mathrm{rodent} \mathrm{chow}$ were provided ad libitum. All experiments were approved by The University of Sydney Animal Ethics Committee.
} 
Biotelemetry transmitters (TA-F10, Data Sciences International, St. Paul, MN) were implanted as according to manufacturer instructions. Briefly, the transmitter was implanted according to the manufacturers protocol into the peritoneal cavity following anaesthization with isoflurane (3\% induction, 1-2\% maintenance). The wound was sutured closed and data collection commenced after 10 days of recovery.

The mice were habituated over multiple days to intraperitoneal injections of vehicle (a solution composed of $7.8 \%$ polysorbate 80 and $92.2 \%$ physiological saline). Injection always occurred at a set time of day (10:00 am). The final vehicle habituation injection was used as a drug-free baseline, to which all drug doses were compared. The mice received injections of 5F-CUMYLP7AICA in an ascending dose sequence $(0.1,0.3,1$, and $3 \mathrm{mg} / \mathrm{kg})$. This ascending sequence was used in order to minimize the risk posed to the animals in assessing hitherto untested compounds. Two washout (drug-free) days were given between each dose to limit development of tolerance.

\begin{abstract}
Antagonist testing was performed similarly, using four additional drug-naïve mice. The mice were implanted with biotelemetry transmitters, habituated to injections, and then pre-treated with either $10 \mathrm{mg} / \mathrm{kg}$ CB1-receptor selective antagonist SR141716 (rimonabant) or vehicle (counterbalanced). Antagonist pre-treatment was given $30 \mathrm{~min}$ prior to $1 \mathrm{mg} / \mathrm{kg}$ 5F-CUMYL-P7AICA injections. A vehicle-vehicle baseline (one vehicle pre-treatment followed by another vehicle injection) was used as baseline.
\end{abstract}


Body temperature data was gathered continuously at $1000 \mathrm{~Hz}$ and organized into 15 minute bins using Dataquest A.R.T. software (version 4.3, Data Sciences International, St. Paul, MN), and analysed using PRISM (Graphpad Software Inc., San Diego, CA).

Results and discussion. The synthesis of $\mathbf{5}$ is shown in Figure 3, while the synthesis of $\mathbf{6}$ and $\mathbf{7}$ is shown in Figure 4. Using a convenient one-pot procedure, indole (8) was first alkylated with 1-bromo-5-fluoropentane, and then converted to the corresponding 3-trifluoroacetylindole (9) by trifluoroacetic anhydride. The crude trifluoroacetylindole intermediate was hydrolyzed to carboxylic acid 10, converted to the corresponding acid chloride using oxalyl chloride, and treated with cumylamine to afford 5F-CUMYL-PICA.

\section{[APPROXIMATE PLACEMENT OF FIGURE 3]}

The synthesis of $\mathbf{6}$ and 7 required a slightly different route and is depicted in Figure 3. Methyl 1H-indazole-3-carboxylate (11) and methyl pyrrolo[2,3-b]pyridine-3-carboxylate (12) were deprotonated with potassium tert-butoxide and treated with 1-bromo-5-fluoropentane to yield the desired 1-alkylated indazole-3-carboxylate (13) and pyrrolo[2,3-b]pyridine-3-carboxylate (14) esters, respectively. Saponification of $\mathbf{1 3}$ and $\mathbf{1 4}$ afforded the corresponding acids $\mathbf{1 5}$ and 16, which were subsequently coupled with cumylamine using EDC-HOBt to give respective amides 6 and 7.

\section{[APPROXIMATE PLACEMENT OF FIGURE 4]}


SCRAs 5, 6, and 7 were analyzed using ${ }^{1} \mathrm{H}$ and ${ }^{13} \mathrm{C}$ nuclear magnetic resonance (NMR) spectroscopy. Full details of these analyses are provided in the experimental section. As expected, ${ }^{1} \mathrm{H}$ NMR spectra for 5, 6, and 7 were similar over the chemical shift range of 0-7 ppm, providing few unique signals for conclusive structural differentiation. In the aromatic region of the spectra, however, several unique signals allowed unambiguous discrimination of the heteroaromatic core of each SCRA (Fig. 5). Most notably, the H-2 protons from 5 and 7 were obvious as singlets and shifted to $7.69 \mathrm{ppm}$ and $7.74 \mathrm{ppm}$ relative to trimethylsilane (TMS), respectively. Indazole 6 , containing a nitrogen atom at the 2 position, showed no signal in this region. Indole 5 contained no signals downfield of a multiplet centered on approximately 7.9 ppm (H-), while H-4 and H-6 of the 7-azaindole core of 7 were each observed as a doublet of doublets centered on $8.27 \mathrm{ppm}$ and $8.36 \mathrm{ppm}$, respectively, and with characteristic ${ }^{3} J_{\mathrm{HH}}$ coupling to H-5 upfield. This is expected for the pyrrolo[2,3-b]pyridine system ${ }^{26}$ and consistent with a previous ${ }^{1} \mathrm{H}$ NMR analysis of 7 obtained by isolation from a SCRA NPS product. ${ }^{27}$ Indazole 6 contained a partially resolved doublet of triplets corresponding to H-4 in the same chemical shift range. Therefore, analysis of the region 7.6 to $8.5 \mathrm{ppm}$ downfield of TMS in the proton NMR spectra should enable simple and rapid discrimination of emergent 7-azaindole-3-carboxamide (7AICA) SCRAs from isomeric indazole analogues in future.

\section{[APPROXIMATE PLACEMENT OF FIGURE 5]}

In order to provide data of relevance to forensic and clinical toxicologists, synthesized $\mathbf{5}, \mathbf{6}$, and $\mathbf{7}$ were also analyzed using GC-MS (Fig. 6) and LC-QTOF-MS (Fig. 7). GC-MS/MS spectra for synthesized 5, 6, and 7 were obtained independently of Energy Control using a method 
developed in our laboratories for the analysis of phytocannabinoids, and some variation in retention time (rt) was expected. The GC-MS total ion chromatograms (TICs) for $\mathbf{5}$, $\mathbf{6}$, and $\mathbf{7}$ showed rt of $9.04,8.09$, and 8.52 minutes, respectively, and the MS fragmentation patterns were consistent with those described by Energy Control. Molecular ions were observed by GC-MS for $5(\mathrm{~m} / \mathrm{z} 366.20), 6(\mathrm{~m} / \mathrm{z} 367.17)$, and $7(\mathrm{~m} / \mathrm{z} 367.16)$, however, these were generally of low abundance ( $<20 \%$ relative intensity). Although the molecular ion of indole $\mathbf{5}$ differed from indazole 6 and azaindoles 7 by a single atomic mass unit (amu), the latter are isobaric and could not be distinguished. Similarly, the base peak for each compound corresponded to the acylium ion formed following loss of the cumylamine group and was observed at $m / z 232.06$ for $\mathbf{5}$, and at one greater amu for $6(\mathrm{~m} / \mathrm{z} 233.06)$ and $7(\mathrm{~m} / \mathrm{z} 233.06)$. Other identifiable peaks include the likely products of a McLafferty rearrangement and subsequent elimination of methylstyrene of 5, 6, and 7 at $\mathrm{m} / \mathrm{z} 248.11,249.09$, and 249.08, respectively, as described for related systems. ${ }^{15}$ The prominent ion $\mathrm{m} / \mathrm{z} 352.15$ observed for $\mathbf{6}$ corresponds to loss of a single methyl group from the cumylamine side chain, likely due to stabilization of the formed tertiary carbocation, but it is unclear why the corresponding ion was not observed for $\mathbf{5}$ or $\mathbf{7}$. Although $\mathbf{6}$ could differentiated from 7 by rt, the mass spectrum fragmentation of these isomers was similar. Therefore, we also analyzed all compounds by LC-QTOF/MS.

\section{[APPROXIMATE PLACEMENT OF FIGURE 6]}

The LC-QTOF/MS elution order for 5, 6, and 7 paralleled that for GC-MS, with retention times of 6.796, 7.121, and 6.280 minutes, respectively. As shown in Figure 7, protonated molecular ions $\left([\mathrm{M}+\mathrm{H}]^{+}\right)$of low abundance were observed for indole $5(\mathrm{~m} / \mathrm{z} 367.2185,3.8 \%$, mass error - 
$0.3 \mathrm{ppm})$ and indazole $6(\mathrm{~m} / \mathrm{z} 368.2129,4.8 \%$, mass error $-2.4 \mathrm{ppm})$, whereas the more basic azaindole 7 exhibited a prominent molecular ion $(\mathrm{m} / \mathrm{z} 368.2086,48.4 \%$, mass error $-6.0 \mathrm{ppm})$. In addition to being more facile in the analysis of forensically relevant biological matrices such as serum and urine, LC-QTOF/MS provides increased resolution over GC-MS for isobaric compounds, demonstrated here for regioisomers 6 and 7. Examination of the fragmentation spectra of 6 and 7 reveal that scaffold-hopping from indazole to the 7-azaindole $(1 H$-pyrrolo[2,3$b]$ pyridine) core is enough to change the relative abundance of the major fragments of these compounds resulting in a reversal of abundances for the fragments $\mathrm{m} / \mathrm{z} 250.13$ and $\mathrm{m} / \mathrm{z} 233.10$, with $\mathrm{m} / \mathrm{z} 250.13$ being the base peak for 7 and $\mathrm{m} / \mathrm{z} 233.10$ being the base peak for 6 . Additionally, 7 is further distinguished by the presence of a unique fragment corresponding to $m / z$ 207.13. The only peak that is common to all three compounds is $m / z 119.08$. The proposed fragmentation pathways shown in Figure 7 are entirely consistent with those described extensively for 6,7 , and related analogues previously. ${ }^{15}$

\section{[APPROXIMATE PLACEMENT OF FIGURE 7]}

The binding affinities and functional activities of $\mathbf{5 , 6}$, and $\mathbf{7}$ at human $\mathrm{CB}_{1}$ and $\mathrm{CB}_{2}$ receptors are shown in Table 1. As anticipated from their structures and existence on the NPS market, 5, 6, and 7 all showed affinity for both $\mathrm{CB}$ receptor subtypes. Indazole $\mathbf{6}$ demonstrated the highest affinity for $\mathrm{CB}_{1}\left(K_{\mathrm{i}}=2.95 \mathrm{nM}\right)$, while the affinity of indole $5\left(K_{\mathrm{i}}=12.6 \mathrm{nM}\right)$ was several times lower, and that of azaindole $7\left(K_{\mathrm{i}}=174 \mathrm{nM}\right)$ was an order of magnitude lower again. All SCRAs also bound to $\mathrm{CB}_{2}\left(K_{\mathrm{i}}=0.76-74.9 \mathrm{nM}\right)$, with affinities approximating those for $\mathrm{CB}_{1}$ in each case. 


\section{[APPROXIMATE PLACEMENT OF TABLE 1]}

The trends for functional activities at $\mathrm{CB}_{1}$ were similar, and all ligands were potent, efficacious agonists, with maximal effects $110-118 \%$ of those elicited by $1 \mu \mathrm{M}$ CP 55,940 . Using the same stably transfected cell lines reported by us previously, indazole 6 was a subnanomolar agonist at $\mathrm{CB}_{1}\left(\mathrm{EC}_{50}=0.43 \mathrm{nM}\right)$, followed by indole $5\left(\mathrm{EC}_{50}=2.8 \mathrm{nM}\right)$, and azaindole $7\left(\mathrm{EC}_{50}=4.7 \mathrm{nM}\right)$. As with binding, all ligands were also potent and efficacious $\mathrm{CB}_{2}$ agonists $\left(\mathrm{EC}_{50}=11.2-39.6\right.$ $\mathrm{nM}$ ). The nanomolar $\mathrm{EC}_{50}$ value for 5F-CUMYL-P7AICA at $\mathrm{CB}_{1}$ ranks it among other potent SCRAs identified in recent years, like AMB-CHMINACA $\left(\mathrm{CB}_{1} K_{\mathrm{i}}=0.339 \mathrm{nM} ; \mathrm{EC}_{50}=5.1 \mathrm{nM}\right)$ and MDMB-FUBINACA $\left(\mathrm{CB}_{1} K_{\mathrm{i}}=0.0985 \mathrm{nM}\right.$; $\left.\mathrm{EC}_{50}=3.9 \mathrm{nM}\right)$, despite demonstrating a binding affinity several orders of magnitude lower than such ligands. ${ }^{19,24}$ The observed affinity and potency trends for the congeneric heteroaromatic series (indazole $>$ indole $>7$-azaindole) are consistent with those of SCRAs featuring alternative 1-substituents and different pendant groups in place of cumylamine. ${ }^{17,24,28}$

The cannabimimetic activity of 5F-CUMYL-PICA in rats was recently reported ${ }^{17,20}$. However, it is not currently known whether the 7-azaindole core of 5F-CUMYL-P7AICA confers cannabinoid activity in vivo. This is especially important due to the difference between $\mathrm{CB}_{1}$ affinity and functional activity reported above for this SCRA. To address this question, the hypothermic effects of 5F-CUMYL-P7AICA in mice were assessed using biotelemetry. 
5F-CUMYL-P7AICA produced clear hypothermia in mice when injected intraperitoneally at 0.3 $\mathrm{mg} / \mathrm{kg}$ or higher (Figure $8 \mathrm{a}$ ). This hypothermic effect was brief, lasting approximately $1 \mathrm{~h}$ irrespective of dose. A dose of $3 \mathrm{mg} / \mathrm{kg}$ caused profound hypothermia, where body temperature fell approximately $6{ }^{\circ} \mathrm{C}$ below baseline. Additionally, pre-treatment with $10 \mathrm{mg} / \mathrm{kg}$ SR141716 (rimonabant) blocked the hypothermia elicited by $1 \mathrm{mg} / \mathrm{kg}$ 5F-CUMYL-P7AICA, pointing to a $\mathrm{CB}_{1}$ receptor mediated mechanism, in agreement with in vitro $\mathrm{CB}_{1}$ receptor activity (Figure $8 \mathrm{~b}$ ). Taken together with the in vitro data, biotelemetry suggests that binding affinity alone is not sufficient to predict the in vivo potency of new SCRAs.

\section{[APPROXIMATE PLACEMENT OF FIGURE 8]}

Conclusion. Although the earliest SCRA NPS were repurposed compounds found in the chemical literature, recent structures are often unknown prior to first detection in the NPS market, and often appear to be the products of rational design using medicinal chemistry techniques such as scaffold hopping. Synthetic methods for preparation of reference standards for scaffold hopping SCRAs 5F-CUMYL-PICA, 5F-CUMYL-PINACA, 5F-CUMYL-P7AICA was developed, and these methods should be general for related carboxamide SCRAs featuring indole, indazole, and 7-azaindole cores. 5F-CUMYL-PICA, 5F-CUMYL-PINACA, 5FCUMYL-P7AICA were differentiated by GC-MS, and more easily by LC-QTOF-MS, due to differences in fragmentation patterns in both modalities. Despite similar structures, these SCRAs showed dramatic differences in $\mathrm{CB}_{1}$ binding affinity, with the 7-azaindole core of 5F-CUMYLP7AICA conferring reduced affinity and functional activity compared to the indazole or indole cores of 5F-CUMYL-PINACA and 5F-CUMYL-PICA, respectively. Despite this, 5F-CUMYL- 
P7AICA demonstrated potent hypothermic effects in mice through a $\mathrm{CB}_{1}$-dependent mechanism, confirming the activity of this SCRA in vivo. Since scaffold hopping from indole or indazole to the corresponding 7-azaindole does not abolish the cannabimimetic activity of the cumylaminecarboxamide class of SCRAs, we anticipate that this heterocycle will continue to appear as a replacement for indole and indazole cores in emergent SCRA NPS. 


\section{References.}

1. United Nation Office on Drugs and Crime. World Drug Report 2017. United Nations publication, Sales No. E.17.XI.6, 2017. Available at http://www.unodc.org/wdr2017. Accessed 31 January 2018.

2. Langer N, Lindigkeit R, Schiebel HM, Papke U, Ernst L, Beuerle T. Identification and quantification of synthetic cannabinoids in "spice-like" herbal mixtures: Update of the German situation for the spring of 2016. Forensic Sci Int. 2016;269:31-41. https://doi.org/10.1016/j.forsciint.2016.10.023.

3. Adams AJ, Banister SD, Irizarry L, Trecki J, Schwartz M, Gerona R. "Zombie" outbreak caused by the synthetic cannabinoid AMB-FUBINACA in New York. New Engl J Med. 2017;376(3):235-242. https://doi.org/10.1056/NEJMoa1610300.

4. Angerer V, Mogler L, Steitz JP, et al. Structural characterization and pharmacological evaluation of the new synthetic cannabinoid CUMYL-PEGACLONE. Drug Test Anal. 2018;10(3):597-603. https://doi.org/10.1002/dta.2237.

5. Asada A, Doi T, Tagami T, et al. Cannabimimetic activities of cumyl carboxamide-type synthetic cannabinoids. Forensic Toxicol. 2017;36(1):170-177. https://doi.org/10.1007/s11419-017-0374-9.

6. Dobaja M, Grenc D, Kozelj G, Brvar M. Occupational transdermal poisoning with synthetic cannabinoid cumyl-PINACA. Clin Toxicol. 2017;55(3):193-195. https://doi.org/10.1080/15563650.2016.1278224.

7. Staeheli SN, Poetzsch M, Veloso VP, et al. In vitro metabolism of the synthetic cannabinoids CUMYL-PINACA, 5F-CUMYL-PINACA, CUMYL-4CN-BINACA, 5F- 
CUMYL-P7AICA and CUMYL-4CN-B7AICA. Drug Test Anal. 2018;10(1):148-157. https://doi.org/10.1002/dta.2298.

8. European Monitoring Centre for Drugs and Drug Addiction. EMCDDA-Europol 2014 Annual Report on the implementation of Council Decision 2005/387/JHA. Publications Office of the European Union, Luxembourg, 2015. https://doi.org/10.2810/112317.

9. Bowden MJ, Williamson JPB. Preparation of cannabinoid indole and indazole compounds for treating pain and nausea, stimulating appetite, and inducing a positive mood change. World patent 2014167530.

10. European Monitoring Centre for Drugs and Drug Addiction. EMCDDA-Europol 2015 Annual Report on the implementation of Council Decision 2005/387/JHA. Publications Office of the European Union, Luxembourg, 2016. https://doi.org/10.2810/932574.

11. Bohm HJ, Flohr A, Stahl M. Scaffold hopping. Drug Discov Today Technol. 2004;1(3):217-224. https://doi.org/10.1016/j.ddtec.2004.10.009.

12. Sun H, Tawa G, Wallqvist A. Classification of scaffold-hopping approaches. Drug Discov Today. 2012;17(7-8):310-324. https://doi.org/10.1016/j.drudis.2011.10.024.

13. Blaazer AR, Lange JH, van der Neut MA, et al. Novel indole and azaindole (pyrrolopyridine) cannabinoid (CB) receptor agonists: design, synthesis, structureactivity relationships, physicochemical properties and biological activity. Eur J Med Chem. 2011;46(10):5086-5098. https://doi.org/10.1016/j.ejmech.2011.08.021.

14. Qian Z, Jia W, Li T, Hua Z, Liu C. Identification and analytical characterization of four synthetic cannabinoids ADB-BICA, NNL-1, NNL-2, and PPA(N)-2201. Drug Test Anal. 2017;9(1):51-60. https://doi.org/10.1002/dta.1990. 
15. Bovens M, Bissig C, Staeheli SN, Poetzsch M, Pfeiffer B, Kraemer T. Structural characterization of the new synthetic cannabinoids CUMYL-PINACA, 5F-CUMYLPINACA, CUMYL-4CN-BINACA, 5F-CUMYL-P7AICA and CUMYL-4CN-B7AICA. Forensic Sci Int. 2017;281:98-105. https://doi.org/10.1016/j.forsciint.2017.10.020.

16. Liu C, Jia W, Hua Z, Qian Z. Identification and analytical characterization of six synthetic cannabinoids NNL-3, 5F-NPB-22-7N, 5F-AKB-48-7N, 5F-EDMB-PINACA, EMB-FUBINACA, and EG-018. Drug Test Anal. 2017;9(8):1251-1261. https://doi.org/10.1002/dta.2160.

17. Longworth M, Banister SD, Boyd R, et al. Pharmacology of cumyl-carboxamide synthetic cannabinoid new psychoactive substances (NPS) CUMYL-BICA, CUMYLPICA, CUMYL-5F-PICA, CUMYL-5F-PINACA, and their analogues. ACS Chem Neurosci. 2017;8(10):2159-2167. https://doi.org/10.1021/acschemneuro.7b00267.

18. Gamage TF, Farquhar CE, Lefever TW, et al. Molecular and behavioral pharmacological characterization of abused synthetic cannabinoids MMB- and MDMB-FUBINACA, MN18, NNEI, CUMYL-PICA, and 5-Fluoro-CUMYL-PICA. J Pharmacol Exp Ther. 2018;365(2):437-446. https://doi.org/10.1124/jpet.117.246983.

19. Schoeder CT, Hess C, Madea B, Meiler J, Müller CE. Pharmacological evaluation of new constituents of "Spice": synthetic cannabinoids based on indole, indazole, benzimidazole and carbazole scaffolds. Forensic Toxicol. 2018 (in press). https://doi.org/10.1007/s11419-018-0415-z.

20. Kevin RC, Lefever TW, Snyder RW, et al. In vitro and in vivo pharmacokinetics and metabolism of synthetic cannabinoids CUMYL-PICA and 5F-CUMYL-PICA. Forensic Toxicol. 2017;35(2):333-347. https://doi.org/10.1007/s11419-017-0361-1. 
21. Banister SD, Stuart J, Kevin RC, et al. Effects of bioisosteric fluorine in synthetic cannabinoid designer drugs JWH-018, AM-2201, UR-144, XLR-11, PB-22, 5F-PB-22, APICA, and STS-135. ACS Chem Neurosci. 2015;6(8):1445-1458. https://doi.org/10.1021/acschemneuro.5b00107.

22. Finlay DB, Cawston EE, Grimsey NL, et al. Gas signalling of the CB1 receptor and the influence of receptor number. $B r \quad J$ Pharmacol. 2017;174(15):2545-2562. https://doi.org/10.1111/bph.13866.

23. Grimsey NL, Goodfellow CE, Dragunow M, Glass M. Cannabinoid receptor 2 undergoes Rab5-mediated internalization and recycles via a Rab11-dependent pathway. Biochim Biophys Acta. 2011;1813(8):1554-1560. https://doi.org/10.1016/j.bbamcr.2011.05.010.

24. Banister SD, Longworth M, Kevin R, et al. Pharmacology of valinate and tert-leucinate synthetic cannabinoids 5F-AMBICA, 5F-AMB, 5F-ADB, AMB-FUBINACA, MDMBFUBINACA, MDMB-CHMICA, and their analogues. ACS Chem Neurosci. 2016;7(9):1241-1254. https://doi.org/10.1021/acschemneuro.6b00137.

25. Knapman A, Santiago M, Du YP, Bennallack PR, Christie MJ, Connor M. A continuous, fluorescence-based assay of mu-opioid receptor activation in AtT-20 cells. J Biomol Screen. 2013;18(3):269-276. https://doi.org/10.1177/1087057112461376.

26. Cox RH, Sankar S. 1H and 13C NMR studies of 7-azaindole and related compounds. Org Mag Res. 1980;14(2):150-152. https://doi.org/10.1002/mrc.1270140216.

27. Ernst L, Brandhorst K, Papke U, et al. Identification and quantification of synthetic cannabinoids in 'spice-like' herbal mixtures: Update of the German situation in early 2017. Forensic Sci Int. 2017;277:51-58. https://doi.org/10.1016/j.forsciint.2017.05.019. 
28. Banister SD, Moir M, Stuart J, et al. Pharmacology of indole and indazole synthetic cannabinoid designer drugs AB-FUBINACA, ADB-FUBINACA, AB-PINACA, ADBPINACA, 5F-AB-PINACA, 5F-ADB-PINACA, ADBICA, and 5F-ADBICA. ACS Chem Neurosci. 2015;6(9):1546-1559. https://doi.org/10.1021/acschemneuro.5b00112. 


\section{Figures and Tables.}

Figure 1. Selected synthetic cannabinoid receptor agonist (SCRA) new psychoactive substances (NPS).

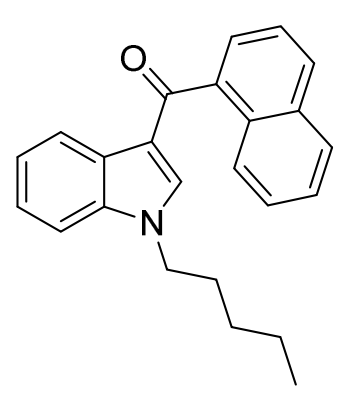

JWH-018 (1)

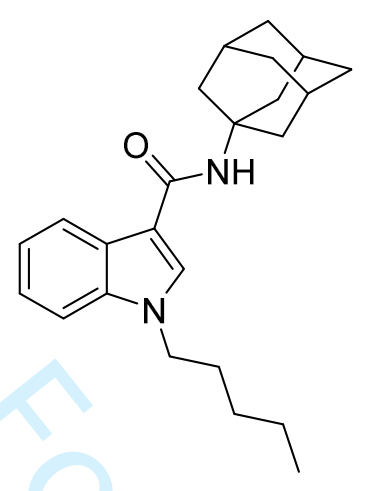

APICA (2)

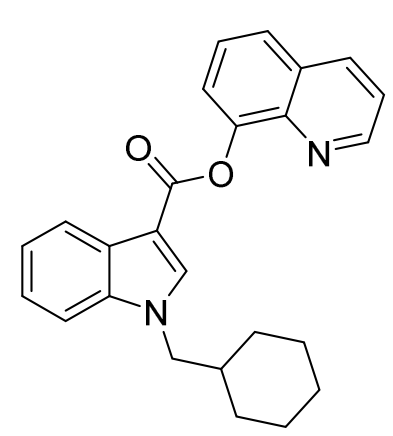

BB-22 (3)

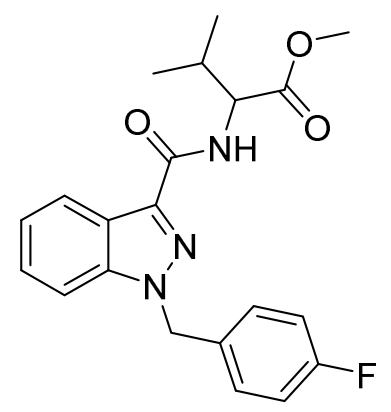

AMB-FUBINACA (4)

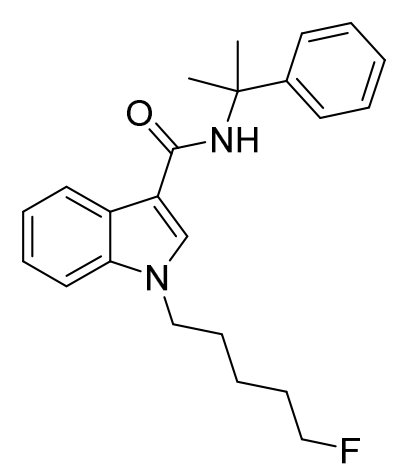

5F-CUMYL-PICA (5)

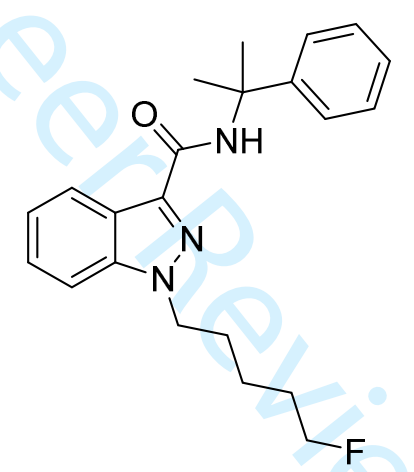

5F-CUMYL-PINACA (6)

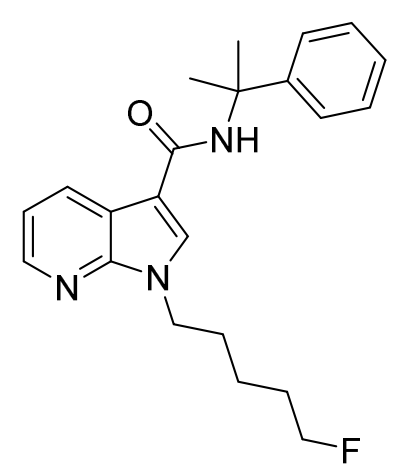

5F-CUMYL-P7AICA (7) 
Figure 2. (a) Packaging of "Rasta King" product obtained by test purchase, and (b) GC-MS TIC and fragmentation spectrum of 5F-CUMYL-P7AICA detected in "Rasta King” by Energy Control.

(a)

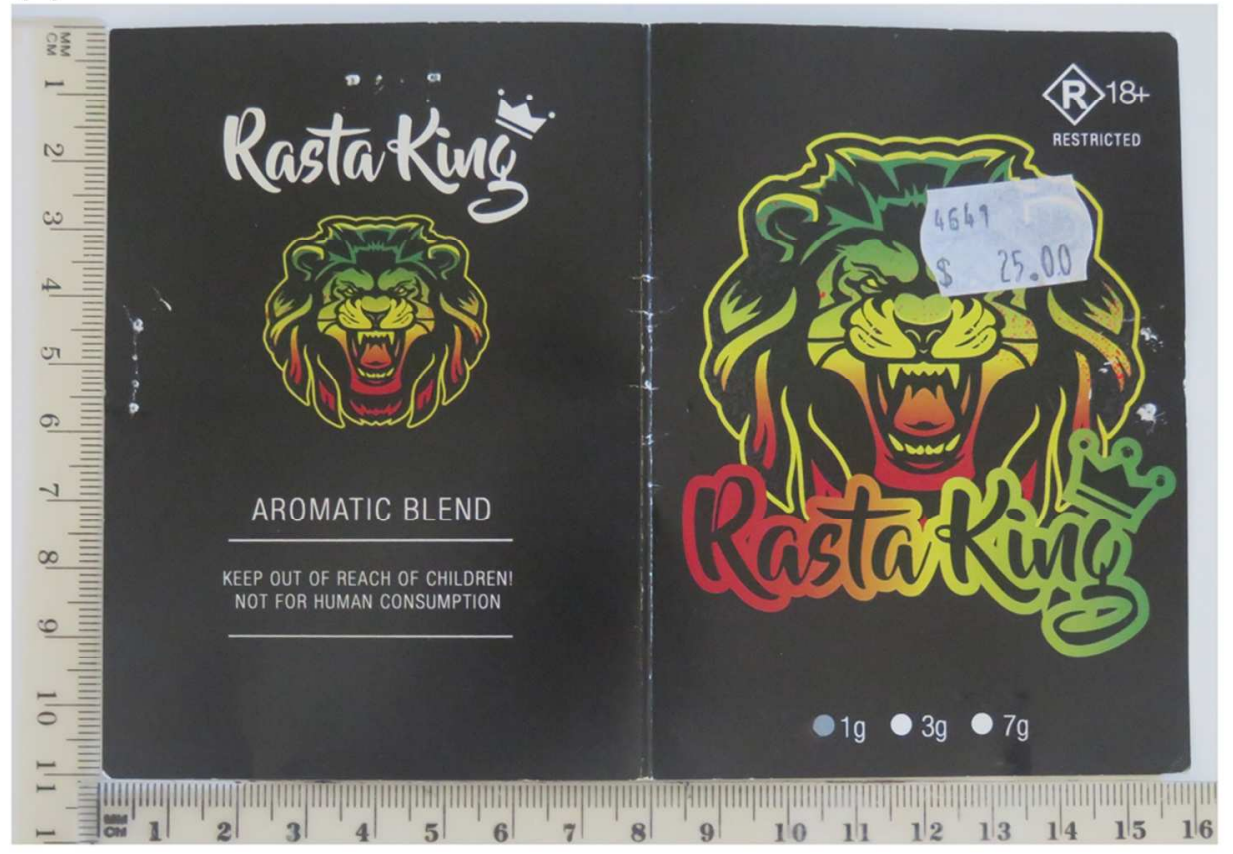

(b)
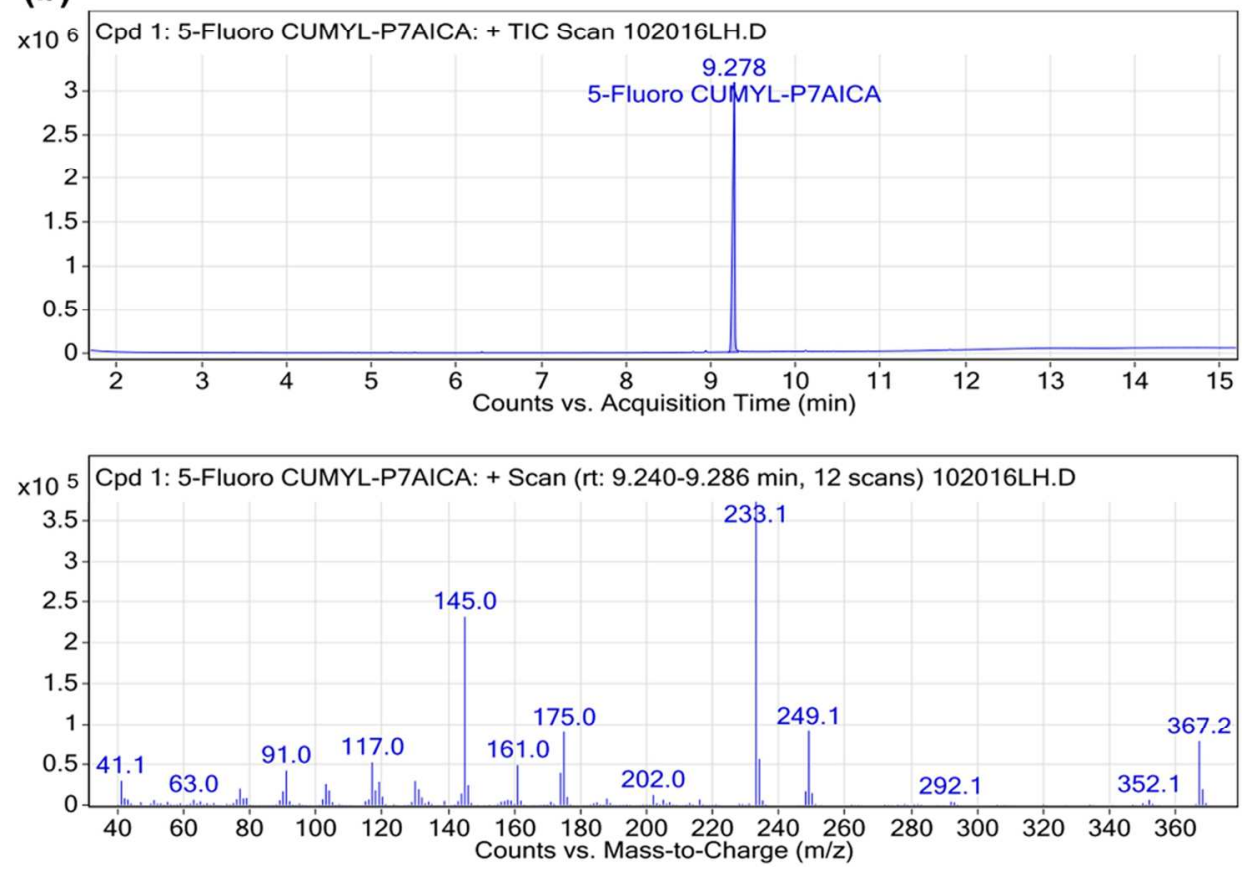
Figure 3. Reagents and conditions: (a)(i) $\mathrm{NaH}, \mathrm{Br}\left(\mathrm{CH}_{2}\right)_{5} \mathrm{~F}$, DMF, $0{ }^{\circ} \mathrm{C}-\mathrm{rt}, 1 \mathrm{~h}$; (ii) $\left(\mathrm{CF}_{3} \mathrm{CO}\right)_{2} \mathrm{O}, 0$ ${ }^{\circ} \mathrm{C}-\mathrm{rt}, 1 \mathrm{~h}$; (b) $\mathrm{KOH}, \mathrm{MeOH}, \mathrm{PhMe}$, reflux, 2 h, 67\% over 3 steps; (c) $(\mathrm{COCl})_{2}$, DMF (cat.), $\mathrm{CH}_{2} \mathrm{Cl}_{2}, 0{ }^{\circ} \mathrm{C}-\mathrm{rt}, 2 \mathrm{~h}$; (d) $\mathrm{PhC}\left(\mathrm{CH}_{3}\right)_{2} \mathrm{NH}_{2}, \mathrm{Et}_{3} \mathrm{~N}, \mathrm{CH}_{2} \mathrm{Cl}_{2}, 0{ }^{\circ} \mathrm{C}-\mathrm{rt}, 14 \mathrm{~h}, 78 \%$.

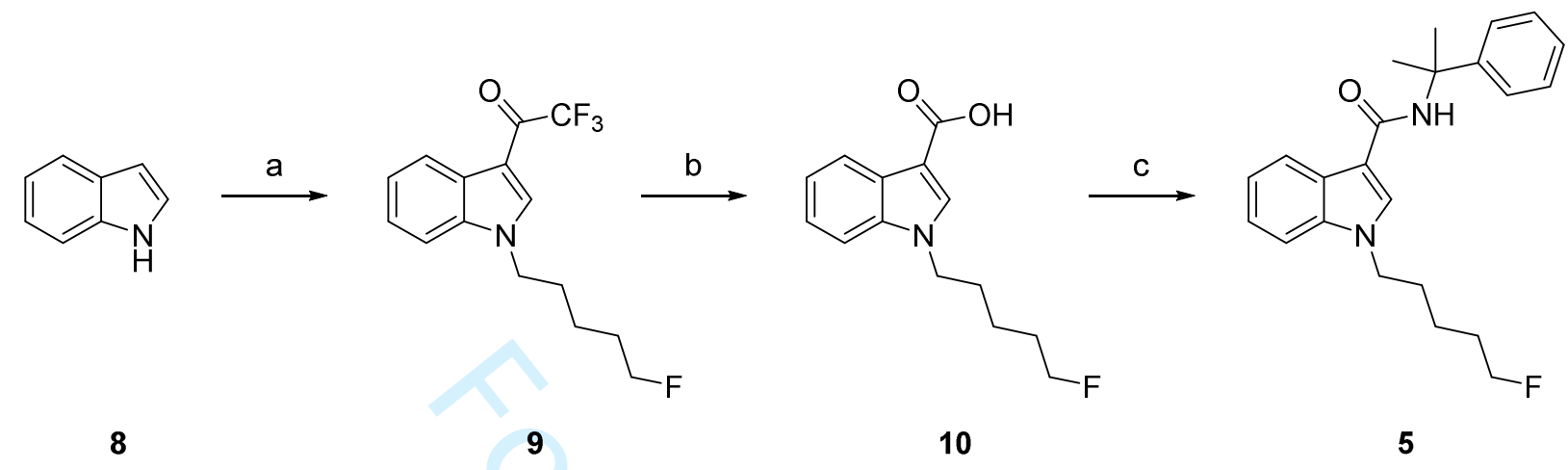


Figure 4. Reagents and conditions: (a) $\mathrm{KO}^{t} \mathrm{Bu}, \mathrm{F}\left(\mathrm{CH}_{2}\right)_{5} \mathrm{Br}$, THF, $0{ }^{\circ} \mathrm{C}-\mathrm{rt}, 14 \mathrm{~h},(\mathbf{1 3}$ : 78\%; 14 : 66\%; (b) $1 \mathrm{M}$ aq. $\mathrm{NaOH}, \mathrm{MeOH}, \mathrm{rt}, 16$ h, (15: 98\%; 16: 94\%); (c) $\mathrm{EDC} \cdot \mathrm{HCl}, \mathrm{HOBt} \cdot \mathrm{H}_{2} \mathrm{O}$, $\mathrm{PhC}\left(\mathrm{CH}_{3}\right)_{2} \mathrm{NH}_{2}, \mathrm{Et}_{3} \mathrm{~N}, \mathrm{DMF}, \mathrm{rt}, 13$ h, 90\% (6: 82\%; 7: 81\%).

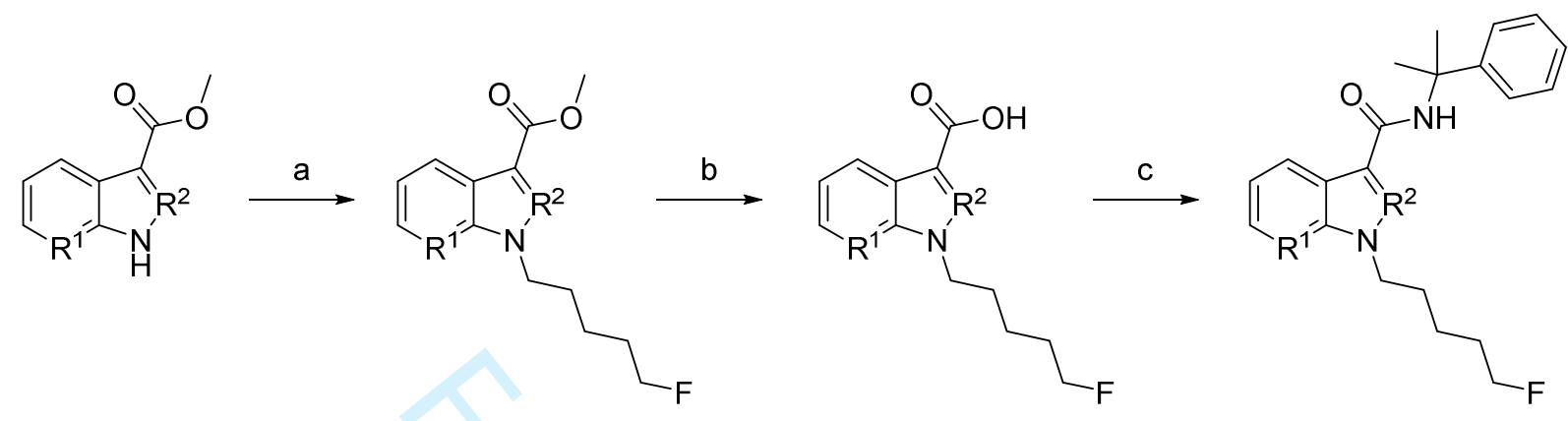
11: $\mathrm{R}^{1}=\mathrm{CH} ; \mathrm{R}^{2}=\mathrm{N}$
13: $\mathrm{R}^{1}=\mathrm{CH} ; \mathrm{R}^{2}=\mathrm{N}$
15: $R^{1}=C H ; R^{2}=N$
6: $\mathrm{R}^{1}=\mathrm{CH} ; \mathrm{R}^{2}=\mathrm{N}$
12: $\mathrm{R}^{1}=\mathrm{N} ; \mathrm{R}^{2}=\mathrm{CH}$
14: $R^{1}=\mathrm{N} ; \mathrm{R}^{2}=\mathrm{CH}$
16: $R^{1}=N ; R^{2}=C H$
7: $\mathrm{R}^{1}=\mathrm{N} ; \mathrm{R}^{2}=\mathrm{CH}$ 
Figure 5. Expansions of the aromatic regions of the ${ }^{1} \mathrm{H} \mathrm{NMR}\left(400 \mathrm{MHz}, \mathrm{CDCl}_{3}\right)$ spectra for (a) 5, (b) 6, and (c) 7. All spectra calibrated to residual $\mathrm{CHCl}_{3}(\delta 7.26 \mathrm{ppm})$.

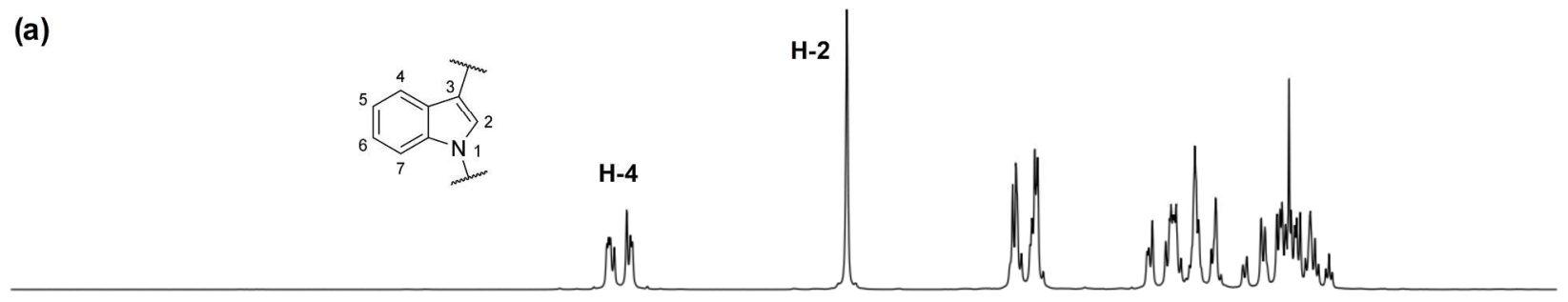

(b)

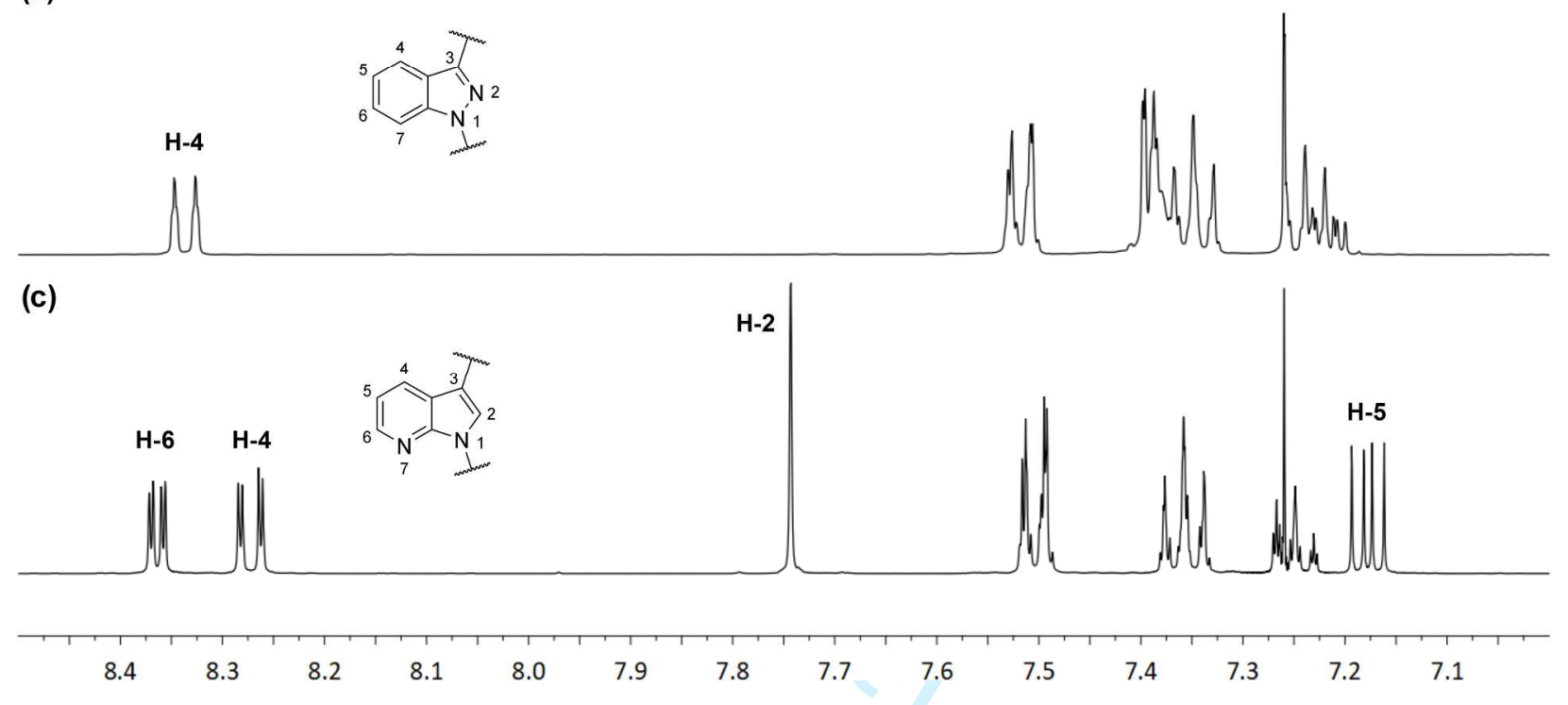


Figure 6. GC-MS ESI mass spectra fragmentation for (a) 5F-CUMYL-PICA, (b) 5F-CUMYLPINACA, and (c) 5F-CUMYL-P7AICA.

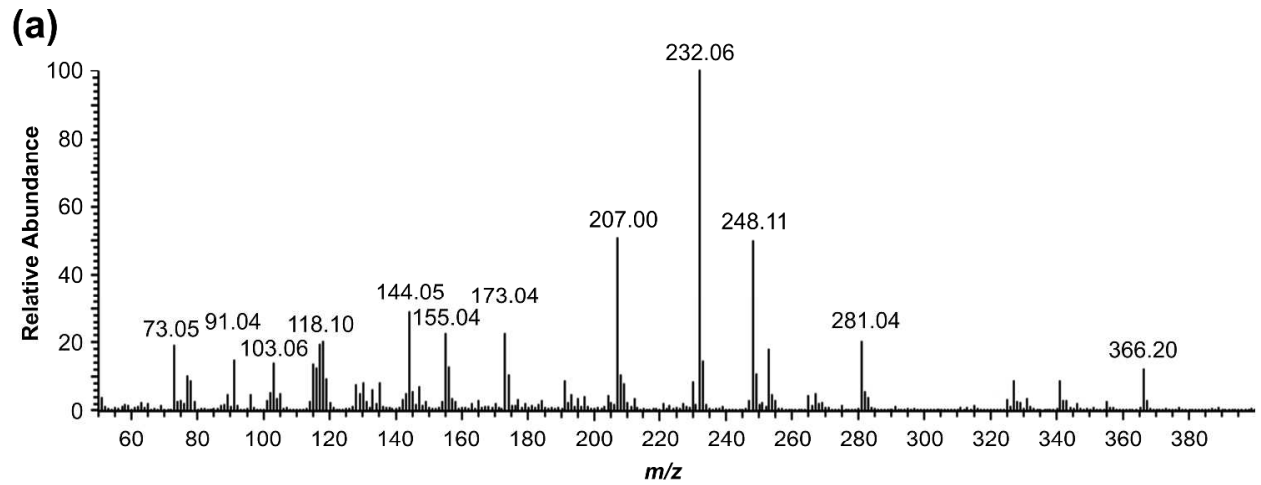

(b)
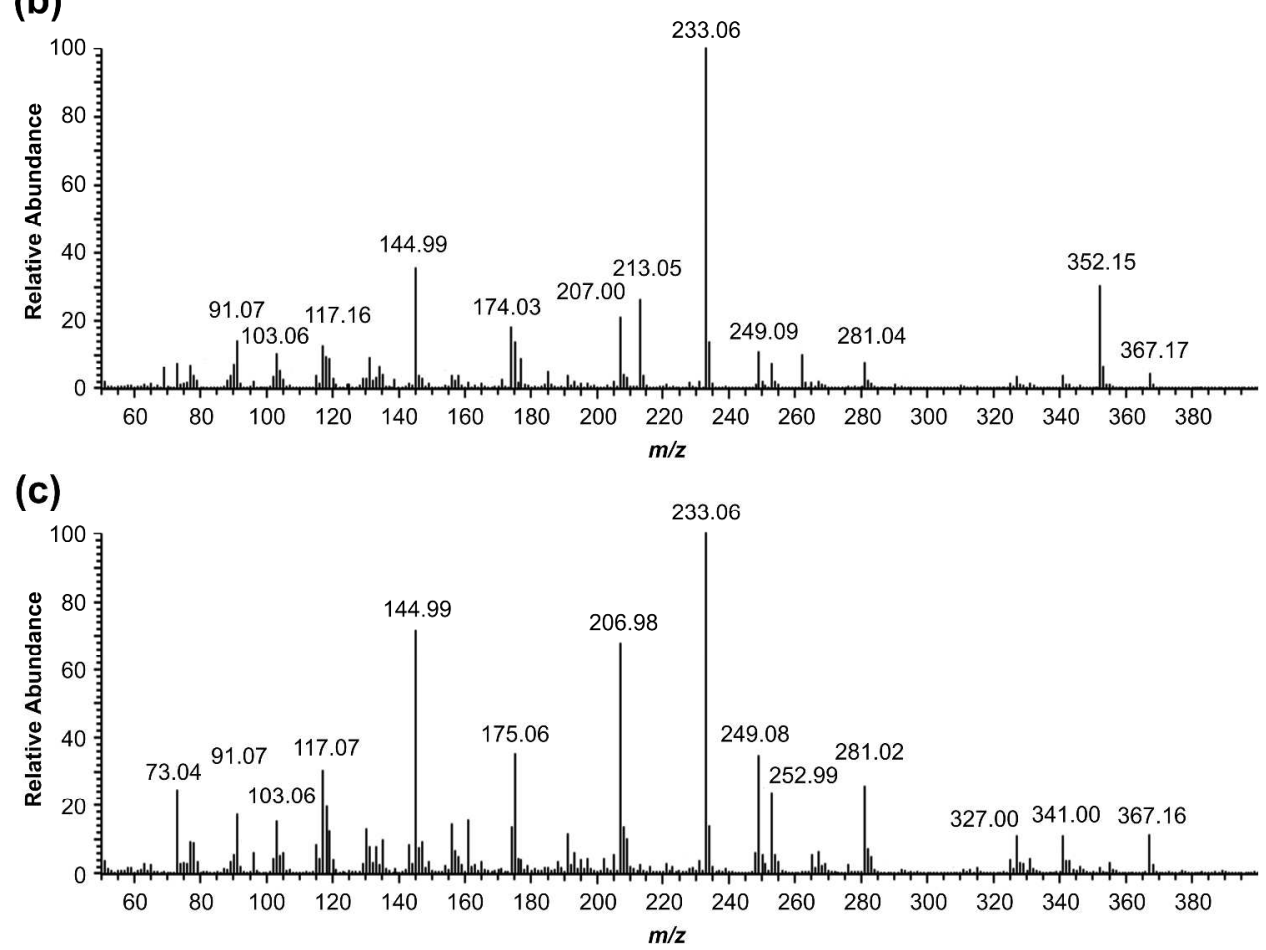
Figure 7. LC-QTOF-MS mass spectra and proposed fragmentations for (a) 5F-CUMYL-PICA, (b) 5F-CUMYL-PINACA, and (c) 5F-CUMYL-P7AICA.

(a)

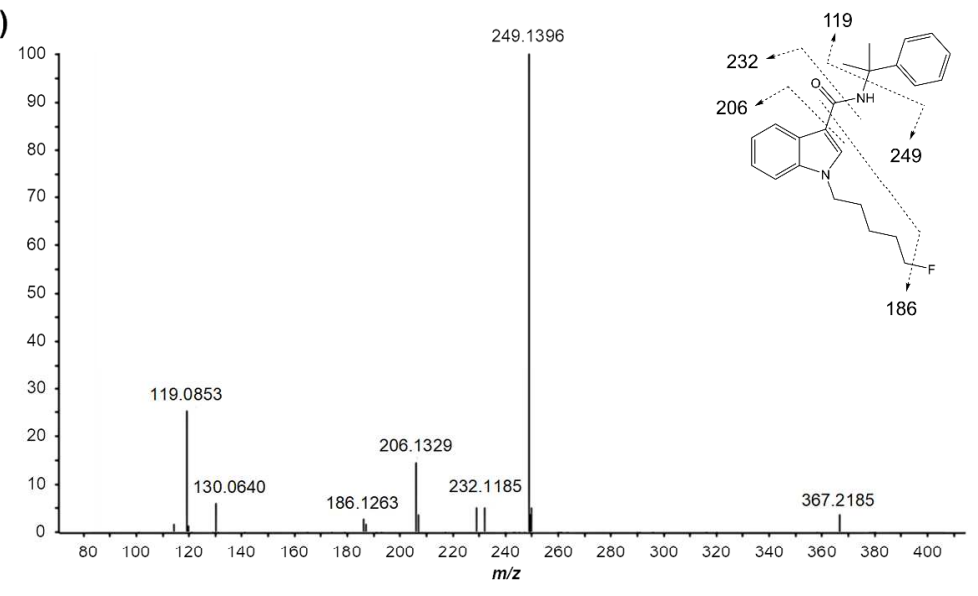

(b)

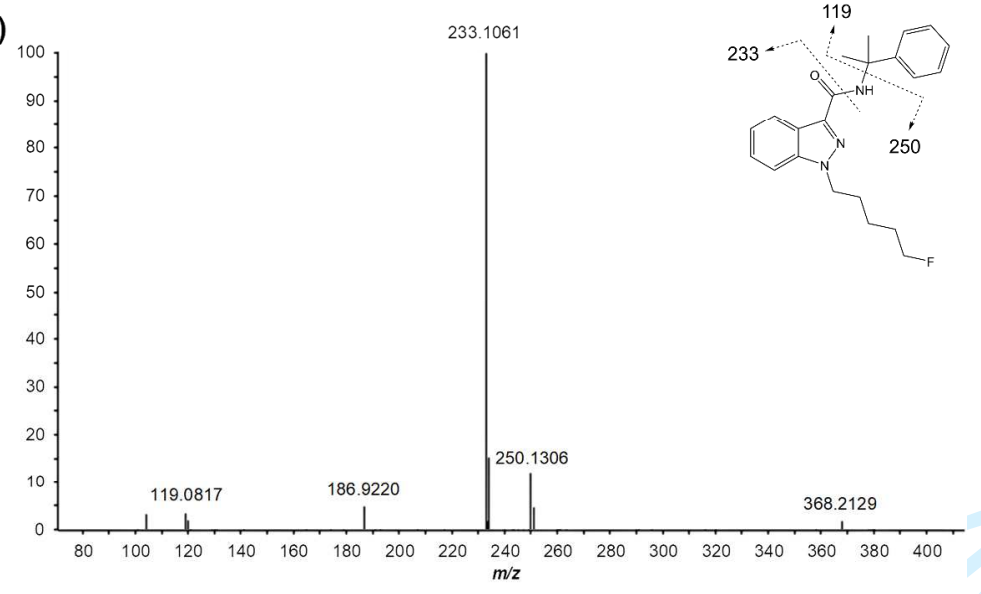

(c)

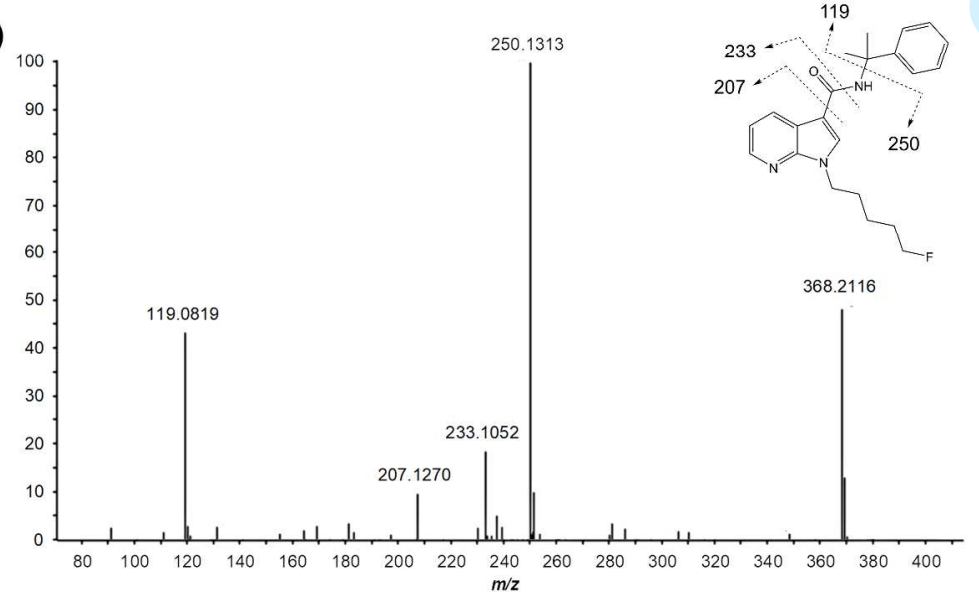

http://mc.manuscriptcentral.com/dta 
Figure 8. Mice body temperature following intraperitoneal injection (dashed line) of (a) 5FCUMYL-P7AICA and (b) $1 \mathrm{mg} / \mathrm{kg}$ 5F-CUMYL-P7AICA following pre-treatment with either drug-free vehicle solution or with $10 \mathrm{mg} / \mathrm{kg}$ SR141716 (rimonabant). All shown as difference from drug-free baseline injections (mean \pm SEM; $n=4)$.

(a)

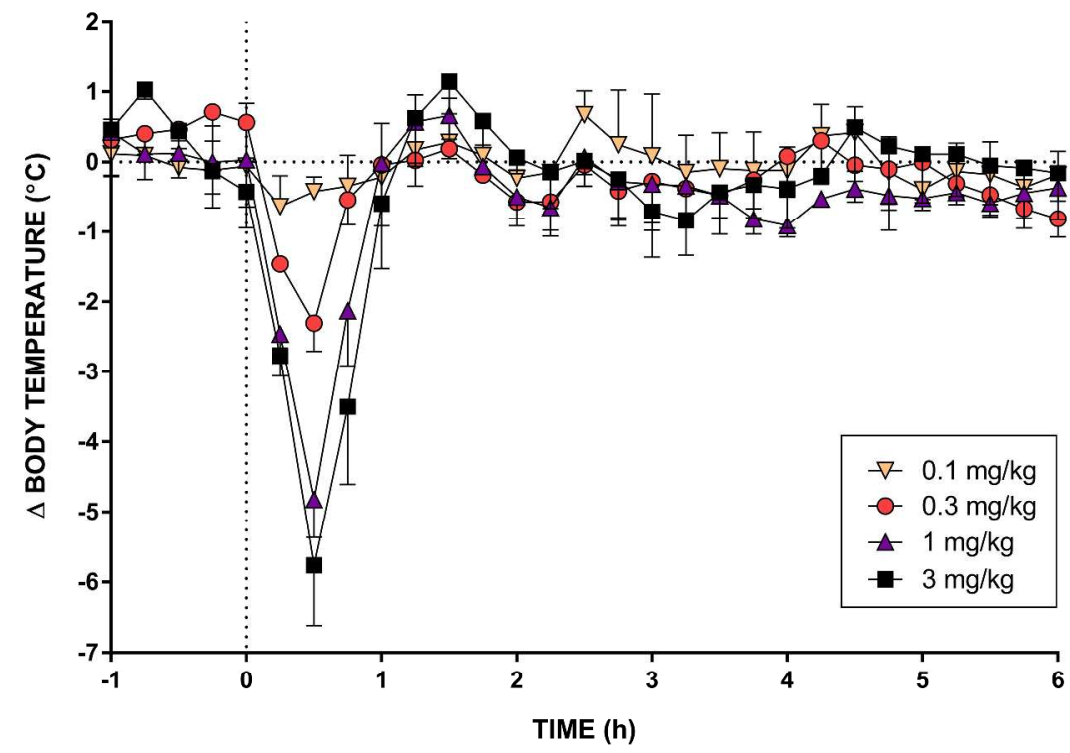

(b)

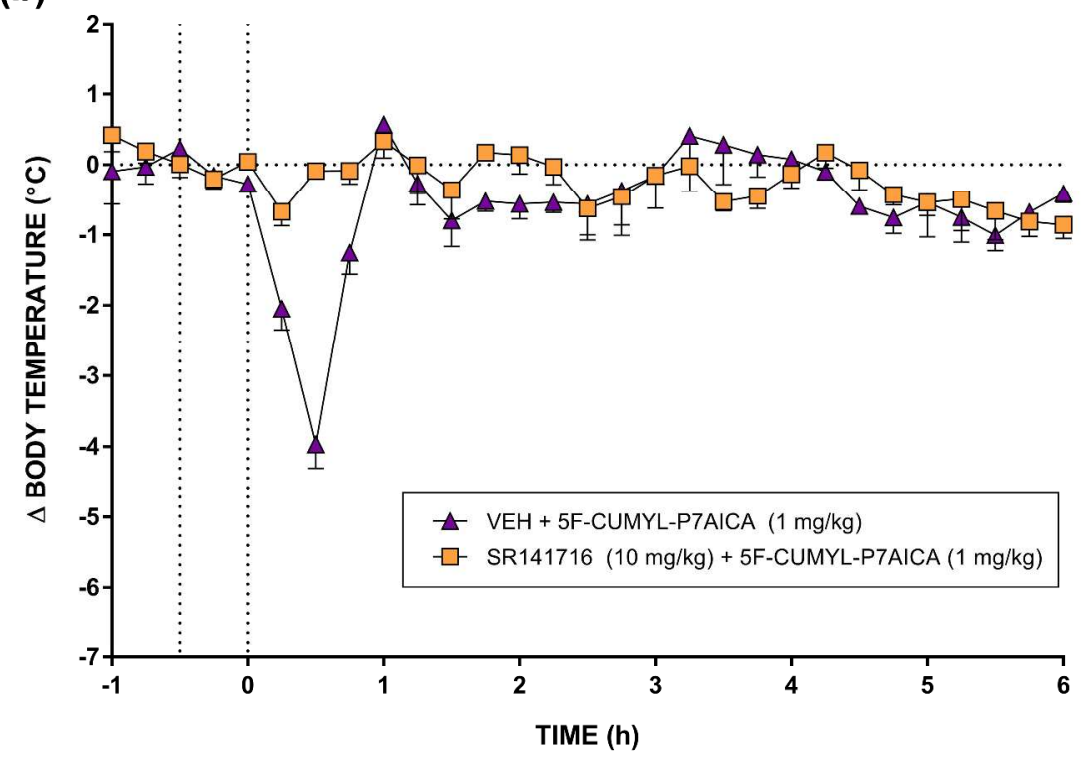


Table 1. Binding affinities and functional activities of SCRAs 5,6 , and 7 at hCB 1 and $\mathrm{hCB}_{2}$ receptors.

\begin{tabular}{|c|c|c|c|c|c|c|}
\hline \multirow[b]{2}{*}{ Compound } & \multicolumn{3}{|c|}{$\mathrm{hCB}_{1}$} & \multicolumn{3}{|c|}{$\mathrm{hCB}_{2}$} \\
\hline & $\begin{array}{c}\text { p } K_{\mathrm{i}} \pm \\
\operatorname{SEM}\left(K_{\mathrm{i}},\right. \\
\mathbf{n M})\end{array}$ & $\begin{array}{c}\mathrm{pEC}_{50} \pm \\
\mathrm{SEM} \\
\left(\mathrm{EC}_{50}\right. \\
\mathrm{nM})\end{array}$ & $\begin{array}{c}\text { Max } \pm \text { SEM } \\
(\% \text { CP } \\
55,940)\end{array}$ & $\begin{array}{c}\text { pK } K_{\mathrm{i}} \pm \\
\operatorname{SEM}\left(K_{\mathrm{i}},\right. \\
\mathbf{n M})\end{array}$ & $\begin{array}{c}\mathrm{pEC}_{50} \pm \\
\text { SEM } \\
\left(\mathrm{EC}_{50}\right. \\
\mathbf{n M})\end{array}$ & $\begin{array}{c}\text { Max } \pm \text { SEM } \\
(\% \text { CP } \\
55,940)\end{array}$ \\
\hline $\begin{array}{c}\text { 5F-CUMYL- } \\
\text { PICA (5) }\end{array}$ & $\begin{array}{l}7.90 \pm \\
0.09 \\
(12.6)\end{array}$ & $\begin{array}{c}8.55 \pm 0.05 \\
(2.8)^{\mathrm{a}}\end{array}$ & $118 \pm 2^{a}$ & $\begin{array}{c}7.86 \pm \\
0.08 \\
(13.8)\end{array}$ & $\begin{array}{c}7.40 \pm 0.10 \\
(39.6)^{\mathrm{a}}\end{array}$ & $104 \pm 5^{\mathrm{a}}$ \\
\hline $\begin{array}{l}\text { 5F-CUMYL- } \\
\text { PINACA (6) }\end{array}$ & $\begin{array}{l}8.53 \pm \\
0.04 \\
(2.95)\end{array}$ & $\begin{array}{c}9.37 \pm 0.06 \\
(0.43)^{\mathrm{a}}\end{array}$ & $110 \pm 3^{a}$ & $\begin{array}{l}9.12 \pm \\
0.12 \\
(0.76)\end{array}$ & $\begin{array}{c}7.95 \pm 0.09 \\
(11.2)^{\mathrm{a}}\end{array}$ & $87 \pm 3^{\mathrm{a}}$ \\
\hline $\begin{array}{l}\text { 5F-CUMYL- } \\
\text { P7AICA (7) }\end{array}$ & $\begin{array}{l}6.76 \pm \\
0.18 \\
(174)\end{array}$ & $\begin{array}{c}8.33 \pm 0.05 \\
(4.7)\end{array}$ & $110 \pm 3$ & $\begin{array}{c}7.12 \pm \\
0.14 \\
(75.9)\end{array}$ & $\begin{array}{c}7.95 \pm 0.09 \\
(11.3)\end{array}$ & $90 \pm 3$ \\
\hline
\end{tabular}

${ }^{\mathrm{a}}$ Data extracted from reference 17. 